\title{
Territorio, violencia y desastres en Colombia: un acercamiento a la memoria histórica ambiental*
}

\author{
Territory, Violence and Disasters in Colombia: \\ An Approach to the Historical Environmental Memory \\ Território, violência e desastres na Colômbia: \\ uma abordagem da memória histórica ambiental
}

Javier Enrique Thomas Bohórquez ${ }^{* *}$

Recibido: 3 de diciembre de 2021

Aprobado: 12 de marzo de 2021

https://doi.org/10.12804/revistas.urosario.edu.co/territorios/a.8742

Para citar este artículo

Thomas Bohórquez, J. E. (2021). Territorio, violencia y desastres en Colombia: un acercamiento a la memoria histórica ambiental. Territorios, (45), 261-292. https://doi.org/10.12804/revistas.urosario. edu.co/territorios/a.8742

\begin{abstract}
* Este trabajo hace parte de resultados parciales de la investigación "La Memoria Histórica Ambiental en el paisaje de la Paz”, desarrollada por el Grupo de Investigación Armero 85, del Departamento de Geografía de la Universidad del Valle.

* Profesor Titular, Departamento de Geografia, Universidad del Valle, Cali, Colombia. Doctor en Geografía Universidad Nacional Autónoma de México. Correo electrónico: javier. thomas@correounivalle. edu.co. ORCID: https:// orcid.org/0000-00015404-7574
\end{abstract}


Palabras clave

Memoria histórica ambiental; territorio; violencia; desastres; Colombia.

Keywords

Historical environmental memory; territory; violence; disasters; Colombia.

Palavras-chave Memória histórica ambiental; território; violência; desastres; Colômbia.

territarias 45

\section{RESUMEN}

El proceso de violencia rural de casi seis décadas que vivió Colombia dejó, a lo largo de su historia, profundas cicatrices sociales, culturales y por supuesto ambientales; este artículo expone algunas reflexiones de un proyecto de que pretendió significar la violencia ambiental y los desastres concomitantes a ella, ocurridos en el país, y aquello que requeriría la construcción social de una memoria histórica ambiental. La relación compleja entre condiciones sociales, políticas y geoestratégicas, con las naturales, también diversas, establecen, de una parte, emergencia de vulnerabilidades ante eventos potencialmente destructivos, de significativos porcentajes de población rural, y de otra, importantes, vastos y a veces irrecuperables impactos ambientales, que exigen mayores niveles de consciencia frente a lo que sería la naturaleza como víctima y los procesos de verdad, justicia, reparación y no repetición de acciones que la degraden en su integridad.

\section{Abstract}

The process of rural violence of almost six decades that Colombia lived left, throughout its history, deep social, cultural and of course environmental scars; this paper exposes some reflections of a research project, was intended to mean environmental violence and the concomitant disasters that occurred in the country and what would require the social construction of a historical environmental memory. The complex relationship between social, political and geostrategic conditions, with the naturals, also diverse, establish, on the one hand, emergence of vulnerabilities to potentially destructive events, significant percentages of rural population, and on the other, important, vast and sometimes unrecoverable impacts environmental, which demand higher levels of awareness about what nature would be as a victim and the processes of truth, justice, reparation and non-repetition of actions that degrade it in its integrity.

\section{RESUMO}

O processo de violência rural de quase seis décadas que a Colômbia viveu, deixou ao longo de sua história profundas cicatrizes sociais, culturais e, claro, ambientais; este artigo apresenta algumas reflexões de um projeto de pesquisa que buscou significar a violência ambiental e os concomitantes desastres ocorridos no país e o que exigiria a construção social de uma memória histórica ambiental. A complexa relação entre as condições sociais, políticas e geoestratégicas, com as condições naturais, também diversas, estabelecem por um lado, o surgimento de vulnerabilidades face a acontecimentos potencialmente destrutivos, de percentagens significativas da população rural, e por outro lado, importantes, vastos e por vezes irrecuperáveis impactos ambientais, que requerem níveis mais elevados de consciência sobre como seria a natureza como vítima e os processos de verdade, justiça, reparação e não repetição de ações que degradem a sua integridade. 


\section{Alrededor del territorio, el conflicto y los desastres}

Referirse en Colombia a una Memoria histórica en el marco del posconflicto, resulta sin duda necesario en un ambiente que clama, cada vez con mayor vigor, unas condiciones de paz reales, duraderas, pero sobre todo justas. La larga historia de violencia que el país ha tenido, los dolorosos matices que ella ha adquirido, los daños personales, familiares y sociales generados, los altísimos costos socioeconómicos y culturales sufridos o las atrocidades cometidas por los grupos en conflicto, no solo implican niveles específicos de responsabilidad social, política y judicial, que han de identificarse, sino también, y de forma preponderante, como condición de justicia, el reconocimiento de los rostros de los victimarios y una memoria que garantice que la voz de las víctimas trascienda más allá de unos hechos y unos tiempos particulares, que permita la visibilización y el reconocimiento de la dimensión social e histórica del conflicto, y, a su vez, propenda por la no impunidad y el resarcimiento a las víctimas. En otras palabras, la memoria no solo es una experiencia vívida del conflicto y por tanto presencia y significado de este en el posconflicto, sino como elemento de denuncia, dignificación del sujeto, afirmación social de las diferencias y posibilidad y medio para la verdad, la justicia y la restauración (CNMH, 2013).
¿Pero si la víctima del conflicto es el territorio, quién expresa su voz? ¿Quién y cómo hace valer sus derechos violentados y pugna por su reparación? ¿Qué o quién materializa o representa sus daños? ¿Qué o a quiénes se resarce? ¿Cómo lograr su dignificación en el marco del conflicto vigente y del posconflicto a construir? A su vez ¿Quiénes son parte o definen el territorio? o, en contraste ¿Quiénes están por fuera o al margen de él? ¿Cuáles son sus derechos vitales por defender o a reparar? ¿Existe o se requiere una memoria histórica territorial? ¿Existe o se requiere una memoria histórica ambiental (MHA)?

Estas preguntas llevan a reseñar, inicialmente, al concepto de territorio; este, en tanto espacio de poder, materializa indefectiblemente los diversos intereses, expectativas y posibilidades que ciertos agentes hegemónicos expresan en él, por él y sobre él, y que generan determinada condición de subordinación de aquellos actores no hegemónicos. Estos últimos, consecutivamente, en procesos de resistencia, adaptación o asimilación, ceden el control parcial o total del espacio a los primeros, reconociendo su incapacidad o limitaciones para igualar o superar su propuesta de ocupación-uso-transformación del espacio. En otros términos, la necesaria interacción social, que se da en el territorio, como resultado mismo del proceso histórico-cultural de apropiación-significación-valoración-dominio del espacio, establece condiciones de subordinación de unos hacia otros, ya sea por 
razones institucionales, sociales, económicas, políticas, étnicas, culturales, etc., que materializan el poder y la forma como este se expresa.

Al reconocer así la connotación política e incluso instrumental del territorio, es posible afirmar que una de sus características inherentes es el conflicto; conflicto que puede o no, según las connotaciones históricas, sociales, culturales e institucionales particulares, derivar en violencia física, simbólica, política, social, cultural o territorial.

Conflicto territorial que puede ser asumido, entre otras interpretaciones: i) como aquellas incompatibilidades entre la oferta ecológica que establecen un uso potencial de los recursos naturales y del suelo, y las lógicas y modelos de explotación de estos, que definen un uso racional, en función de las necesidades y requerimientos de carácter social; ii) a las expresiones sociales, políticas, económicas, institucionales y culturales que favorecen o no el acceso, en condiciones de legitimidad y equidad, a la compleja red de satisfactores, de orden natural y cultural, de estas necesidades; iii) a la creación, permanencia y fortalecimiento de espacios y canales de participación política y social en la toma de decisiones sobre el territorio; iv) al choque de intereses de los diversos grupos que componen la sociedad y que se expresan en formas distintas de imaginar, comprender, apropiarse, sentir, usar y transformar el espacio, o sea, de construir el territorio; v) pero también, y de forma desafortunada para el país, como una forma de control territorial que se ejerce de forma violenta para garantizar que los intereses y beneficios de los grupos hegemónicos, legales o no, no sean retados, modificados o suprimidos por otros agentes marginales, subordinados o emergentes. Esta expresión violenta del conflicto territorial es la que genera mayores costos sociales y culturales, pero también ambientales.

Bien lo reconoce en este sentido, el trabajo realizado por el Grupo de Memoria Histórica cuando afirma:

Los daños materiales y ambientales causan impactos morales y socioculturales. Los bienes materiales son fuentes de reconocimiento y de identidad y garantizan sostenibilidad y supervivencia a las comunidades. Los bienes, especialmente las casas, los enseres y los animales son, en muchas ocasiones, el legado de los ancestros; están cargados de significado, recuerdos y afectos. Para las víctimas, estas pérdidas no representan únicamente un menoscabo financiero sino una pérdida afectiva, de seguridad, de estabilidad; para algunos, incluso, la ruptura del equilibrio con el mundo y la naturaleza. (CNMH, 2013, p. 277)

En esa misma línea de reflexión es posible preguntar ¿́Solamente se afecta naturaleza-territorio a partir de acciones antrópicas, intencionales o no? ¿Los mal llamados desastres naturales (Lavell, 
1993 y 2008; Romero \& Maskrey, 1993; Wilches, 1993; Blaikie et al., 1996; Bohle, 2001; Cutter et al., 2003; Thomas, 2011), tienen algún nivel de relación con los conflictos territoriales mencionados anteriormente? $\mathrm{O}$ ¿Son causa exclusiva de agentes o procesos naturales y, por tanto, están al margen de esta valoración-juicio? ¿Dado su carácter natural, es imposible establecer responsables de ellos y por tanto quien debe reparar a las víctimas es exclusivamente el Estado? ¿Existe alguna correlación entre estas situaciones de desastre y la violencia en el país? ¿Si la hay, de qué tipo es? Y, finalmente, ¿ ¿Deben hacer parte o no, de una memoria histórica que es necesario visibilizar y reconocer? $\mathrm{O}$ ¿Estos eventos, por su condición política neutral, por el dolor que generan y por la necesidad de sanación, los olvidamos y seguimos adelante sin mirar atrás?

De la mano de ello, y convergentemente con esta reflexión, se puede decir que los sistemas biológico-naturales y los socio-culturales no son per se antagónicos o están fracturados, en tanto que, la dimensión material del espacio es contextualizada históricamente a partir de las relaciones sociales de producción (Lefebvre, 1995; Castells, 1976; Harvey, 2008; Santos, 1998; Santos, 2000; Calabi \& Indovina, 1973), definiéndoles valores de uso y de cambio, que establecen un intrincado sistema de relaciones naturaleza-sociedad, donde la primera es resignificada por estimaciones y consideraciones culturales, y que, como segunda naturaleza (Schmidt, 1977), ofrece un cuerpo de posibilidades que los grupos humanos, según su condición de clase, explotan diferencialmente; se define así, un espacio valorado y producido socialmente para ser consumido culturalmente. Con ello confrontamos, como expresa Lussault:

el punto de vista moderno, que consiste en hacer de la naturaleza una instancia autónoma, exterior a la sociedad. Esa necesidad demuestra, muy simplemente, la voluntad de comprender mejor las realidades de la sociedad que nos son accesibles y el lugar que la naturaleza ocupa en ellas [...] Sin embargo, un sismo, en sí, no es un fenómeno social, aunque sí lo es su impacto cuando, por interposición de la onda marítima, desquicia un hábitat humano, y lo es la manera en que cada sociedad integra en su organización y funcionamiento datos relativos a la manifestación de las potenciales consecuencias del sismo sobre el grupo humano. (Lussault, 2007, p. 21)

Si se reconoce entonces la falsa ruptura naturaleza-sociedad, se puede afirmar por ejemplo, que los impactos generados por un tsunami no dependen solamente de la magnitud del sismo o movimiento que lo genere, sino por la particular configuración de los espacios alcanzados por este, definidos por condiciones naturales (geomorfología de la costa y del fondo marino - batimetría-, morfología, morfometría y morfodinámica del 
continente, etc.) y sociales (localización de la población en relación con la línea de costa, equipamientos y usos expuestos, concentración de la población, sistemas de alerta temprana establecidos, etc.); es decir, la connotación particular que adquiere el fenómeno en y por el territorio en mención.

En eso consiste el fenómeno de construcción de la naturaleza. Ella constituye, pues, el conjunto de fenómenos, conocimientos, representaciones, discursos y prácticas que participan y derivan de un proceso de integración social de los datos físicos y biológicos en la sociedad, por ella y para ella y en determinado contexto. Cada sociedad construye artificialmente sus estados naturales, que aseguran una partición, un reparto y un régimen de relación legítimos (aceptados por la mayoría) entre lo humano y lo no humano, entre lo natural y lo social. (Latour, 2001, p. 329)

De hecho, en Sumatra, el 26 de diciembre de 2004, el tsunami “creó un nuevo estado social, otro espacio, inédito y perdurable, que continúa existiendo mucho después del reflujo" (Lussault, 2007 , p. 24); cierta disposición espacial catastrófica, podría decirse, como resultado del evento y la realidad perenne creada.

Con esto se quiere decir, que existe cierta correlación entre el desastre expresado en un espacio-tiempo particular y la situación que lo genera, que implica un cúmulo de circunstancias específicas que se van dando en espacios-tiempos con regularidades dadas; son estas las condiciones de progresividad (Blaikie et al., 1996) y selectividad (Thomas, 2011) inherentes a la construcción de los desastres. Para el caso colombiano operan allí, además de las propias del modelo de desarrollo implementado y las vulnerabilidades económicas, sociales y culturales que conlleva implícito, la violencia territorial como producto de los conflictos que se dan, en especial en áreas rurales, como parte del ejercicio de control territorial que pretenden ejercer ciertos actores armados y que, tarde o temprano, se expresa en las zonas urbanas como ocupación marginal y segregación socio-espacial, ambientes proclives a la materialización de desastres como productos de la construcción social del riesgo.

Al revisar algunas situaciones de desastres, por eventos de origen natural, ocurridos en el país, se pueden sacar algunas conclusiones al respecto. Un listado de los hechos más trágicos traen a la memoria una serie de dolorosos acontecimientos que han marcado duramente nuestra historia: el terremoto de Popayán el jueves santo de 1983; dos años después, el 13 de noviembre, una avenida aluvio-torrencial arrasaría casi por completo la ciudad de Armero en el Tolima, sepultando a más de 25.000 personas; en 1987, el municipio afectado fue el de Medellín, con la tragedia de Villatina, en la que un sector de la ladera nororiental del Cerro Pan de Azúcar se deslizó cuesta abajo, dejando 
aproximadamente 500 personas muertas; el 6 de junio de 1994, un sismo, con epicentro en Toribío en el Cauca, produjo una avalancha en el río Páez que afectó a más de 15 municipios pertenecientes a los departamentos del Cauca y Huila; otro terremoto, el del eje cafetero, esta vez con afectación principalmente en la ciudad de Armenia, dejó en 1999 alrededor de 1300 muertos en los departamentos de Quindío, Risaralda, Caldas, Valle del Cauca y Tolima; ya en este siglo, en los años 2010 y 2011, en un evento de La Niña, hubo inundaciones casi a lo largo y ancho del territorio colombiano, la costa atlántica y algunos sectores de los valles aluviales de los ríos Cauca y Magdalena en los Andes fueron los más afectados, dejando, según informes oficiales, 3.315.653 damnificados; en el año 2017, con una dramática repetición al año siguiente, la ciudad de Mocoa fue el escenario de un nuevo desastre, avenidas torrenciales generadas en los ríos Mocoa, Mulato y Sancoyaco, arrasaron diecisiete barrios de la ciudad, destruyendo al igual, viviendas y obras de infraestructura; el saldo final de muertos fue aproximadamente de 350 en el 2017, y, en el 2018, una importante destrucción de obras realizadas un año atrás como parte de la reconstrucción de la ciudad.

No obstante, en estricto sentido, la lista es más larga y contiene, cuando menos, los terremotos de Huila y Cúcuta en el siglo XIX, los de Tumaco, en 1906, y el de 1979, que originó posteriormente un tsunami; los de Túquerres, también en Nariño, el 9 de enero y 17 de julio de 1936; el deslizamiento de Quebrada Blanca en la vía al llano en 1974, que sepultó a más de 500 personas que se movilizaban por ella; la avenida torrencial sufrida el 25 de noviembre de 1979 en el municipio de El Playón, Santander, que arrasó el pueblo aproximadamente en un $80 \%$, dejando cerca de mil personas afectadas, entre desaparecidos y muertos, y; el deslizamiento de tierra en el Guavio, el 28 de julio de 1983, donde murieron sepultados bajo toneladas de tierra cerca de 200 trabajadores, que construían un túnel de acceso de la represa del Guavio, la más grande del país en ese momento.

Sin embargo, no se encuentran allí los pequeños eventos que silenciosa o cotidianamente ocurren y que generan también importantes afectaciones en pérdidas de vidas, bienes materiales, obras de infraestructura o actividades productivas, como tampoco, aquellos incidentes de origen antrópico, intencionales ${ }^{1}$ o no. ${ }^{2}$ Es decir, no se agota la lista de eventos desastrosos para el país, con los dramáticos eventos relacionados con mayor detalle líneas arriba, y que, demuestran, la significancia que este tipo de eventos tiene en nuestro territorio y la fragilidad que importantes sectores de la población tienen ante ellos.

En unos y otros casos podría preguntarse, nuevamente, si causas de fondo que hicieron posible el desastre estuvieron al margen de condiciones de conflicto territorial o de violencia territorial, y, a la vez, si estas situaciones de desastres producen
Incendios, ataques terroristas a personas $u$ obras de infraestructura o comunicaciones, ataques armados a poblaciones, contaminación de fuentes de agua por agentes quimicos, etc.

${ }^{2}$ Explosiones de estaciones de gasolina, fugas de elementos quimicos, contaminación de fuentes de agua por agentes quimicos, incendios, etc.

territarias 45 267 
algún tipo de violencias territoriales. Las respuestas no son iguales en todos los casos y dada la dificultad de revisar en detalle todos y cada uno, se abordará, a manera de ilustración, la situación en el Putumayo y su capital, Mocoa, con la avalancha del 2017, pero en una perspectiva espacio-temporal mayor, de modo que permita comprender génesis y evolución de los factores amenazantes y de la construcción social de vulnerabilidades, es decir, del desastre, para volver al conflicto y violencias territoriales y su vínculo con la naturaleza y finalizar, con base en este caso, en una reflexión sobre la MHA.

\section{Violencia y desastres en el Putumayo}

Un análisis de las avenidas torrenciales sufridas en Mocoa en el 2017, conocidas popularmente como avalanchas y que, según la gobernadora Sorrel Aroca, "fue un fenómeno natural imprevisible probablemente asociado al cambio climático" (Aroca Rodríguez, 2017), obliga en principio a preguntar ¿Qué tan natural fue este evento?, es decir, ¿hubiera pasado en igual medida y magnitud sin la presencia humana allí? ¿Qué tanto de lo ocurrido responde de forma directa o indirecta a las intervenciones humanas realizadas en las cuencas de los ríos Taruca, Mulato y Sancoyaco? Así mismo, las condiciones que pudieron haber generado, disparado o magnificado el evento, ¿Qué tanto han sido dadas o dependen de factores violentos o expresiones de la violencia - de algún tipo- presente en la zona?

Es posible decir, incluso, que la primera violencia generada en la zona y en toda la superficie del planeta es aquella que rompe las lógicas y tiempos de producción y reproducción de la naturaleza, la que deteriora las propiedades físicas, químicas y biológicas de los elementos naturales (llámense agua, suelo o aire), la que desconoce los ciclos evolutivos de los procesos naturales, imponiendo ritmos artificiales en ellos, asociados a la lógica de circulación y acumulación de capital, y que terminan obviamente degradando los recursos; pero ese es el ineludible costo de la consolidación de la especie humana en el planeta y la concomitante humanización de la naturaleza, por ello, se obviará esta primer expresión de violencia contra la naturaleza diciendo que hemos logrado los avances científicos, tecnológicos y culturales gracias a ella y que, en alguna medida, es un costo que a pesar de ser negativo, asumimos como necesario; lo injustificable allí es el desconocimiento, racional o no, de los límites definidos por estas capacidades naturales de producción, reproducción, asimilación, ajuste y recuperación (homeóstasis y resiliencia) a tal medida que se agoten los recursos, base misma de la existencia humana. Desafortunadamente aún no hemos alcanzado los niveles de consciencia que nos permitan comprender que agredir la naturaleza en esa dimensión es agredirse a sí mismo, pero más importante aún, 
asumir una postura ético-reflexiva que permita respetar las otras especies, per se, en su condición de seres vivos, más allá del utilitarismo que impone la lógica de los bienes naturales.

Evadiendo este planteamiento inicial, se pueden revisar algunas de las circunstancias particulares que podrían haber favorecido el desastre del 2017 en la ciudad de Mocoa, capital del Putumayo.

El departamento del Putumayo presenta condiciones geoestratégicas particulares que propician la presencia de conflictos territoriales, que devienen en violencia territorial; es un espacio fronterizo con Ecuador y Perú, con una rica y compleja geografía selvática; y también es una zona de transición también entre las realidades y posibilidades andinas, $\mathrm{y}$ los vacíos y carencias amazónicas. Posiblemente por estas condiciones geoestratégicas, el Putumayo ha sido: primero, zona de cultivos de coca y de laboratorios de procesamiento de esta; segundo, paso de contrabando de productos diversos, especialmente, de armas e insumos químicos; y tercero, lugar de disputa entre la lógica de acaparamiento de tierras (asociados a proyectos productivos o extractivos de gran escala o megaproyectos de infraestructura) y la de pequeños y medianos campesinos que luchan por posicionar sus productos tradicionales en mercado locales, como de los grupos indígenas que aún sobreviven en la zona ${ }^{3}$ y que pugnan por el acceso a la tierra como capital social, cultural, simbólico y ancestral.
La selva amazónica ofrece, por sus mismas características geográficas, condiciones favorables para la presencia de actividades ilícitas asociadas a narcóticos, cultivos de coca y laboratorios de procesamiento de esta. Justamente, la cartografía de la distribución espacial de los cultivos de coca en el país (UNODC, 2017), mostraba que, para el 2016, una de las áreas más afectadas en Colombia era el departamento del Putumayo (figura 1). Se aprecian allí claramente dos zonas geográficas particulares, una en el alto Putumayo, en el piedemonte de la cordillera de los Andes, y otra en la zona de frontera con el Ecuador. Como se referenciará adelante, la connotación geopolítica de la zona de frontera, juega papel preponderante y explica, en buena parte, este proceso. Los municipios con mayor presencia de plantíos son Puerto Asis, San Miguel y Valle del Guamuez, precisamente la frontera sur; ellos concentran el $61 \%$ de los cultivos del departamento. Además, según la UNODC (2017), Putumayo tenía a diciembre de 2016, 25.162 hectáreas cultivadas de coca; entonces, hoy sigue siendo Putumayo el segundo departamento del país más afectado por cultivos ilícitos, después de Nariño.

Frente a los laboratorios de procesamiento, la información disponible es mucho más limitada, pero documentos oficiales (Gobierno de Colombia, 2004) mencionan que en 2003, se detectaron y destruyeron 1.489 laboratorios, entre laboratorios de base de coca, de cocaina,
Equivalentes a aproximadamente el 13,1\% de la población, representada en 14 pueblos distintos, aglutinados en 126 cabildos y 39 resguardos (Gobernación del Putumayo, 2017) territarias 45 269

TERRITORIO, VIOLENCIA Y DESASTRES EN COLOMBIA: UN ACERCAMIENTO A LA MEMORIA HISTÓRICA AMBIENTAL 
Figura 1. Densidad de cultivos en Colombia y en el Putumayo, 2016

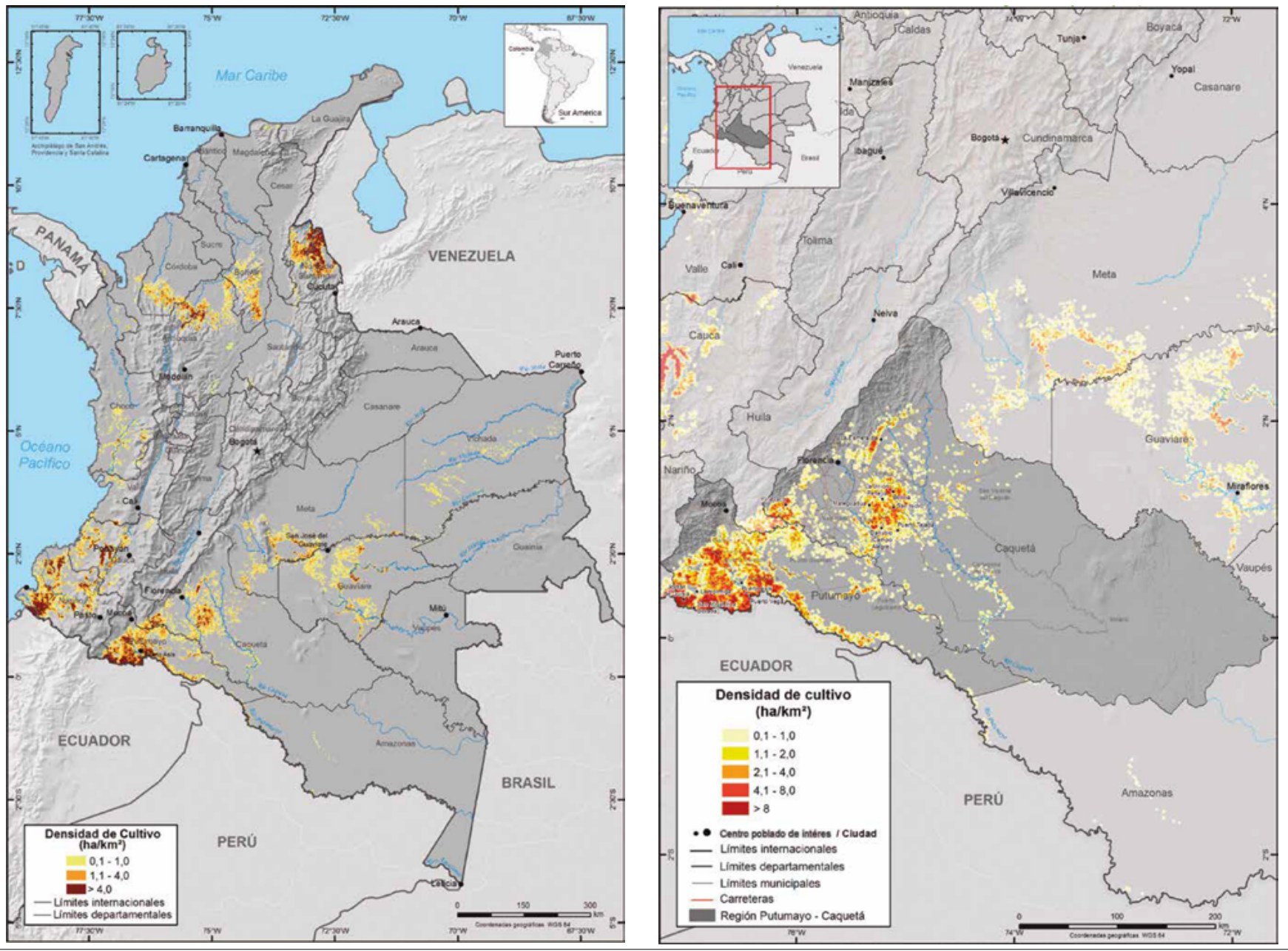

Fuente: UNODC, 2017.

pasta de coca, permanganato de potasio, amoniaco y heroína; aproximadamente el $45 \%$ de ellos localizados en Putumayo. Es de mencionar que los laboratorios no solo buscan la cercanía a los cultivos, sino una

territarias 45 270 productos hacia los mercados de consumo o hacia puntos estratégicos que permitan su circulación posterior; el Putumayo, facilita las dos cosas.

Ello lleva, obligatoriamente, a revisar clave localización para el tráfico de los la condición de frontera, en el contexto 
de las relaciones de poder y equilibrio dinámico de fuerzas, entre el centro y la periferia. Geopolíticamente, el control territorial que se ejerce desde el centro de poder se va diluyendo a medida que se distancia de este. Poder que se expresa en presencia, regulación y control institucional (de un Estado, en este caso), que norma y legitima, en su sentido más amplio, las interacciones sociales, políticas y económicas. Por ello, la frontera per se (a menos que coincida con el centro de poder) será siempre periférica y marginal, como en este caso en particular, respondiendo de forma significativa a lo que Sahlins (1988, citado en Grimson, 2003), ha denominado la estructura de la coyuntura. ${ }^{4}$

Igualmente, la frontera, inherente a su naturaleza cumple las funciones, antagónicas pero complementarias, de continuidad y de ruptura; continuidad, representada en la permeabilidad y difusión de cierto proyecto de nación y territorio, a la vez que la proyección de las funciones de intercambio, que demandan, forzosamente, condiciones de secuencialidad a lado y lado de la línea; en contraste, pero complementariamente, la ruptura se encarna en el control del intercambio que se ejerce a través de los sitios de paso obligados, acordados, formalizados y legitimados conjuntamente, y que cierran otros puntos de la línea, en los que se pueden instalar, o pasar, dependiendo de la presencia y control territorial formal, actividades y/o dinámicas no institucionales o ilícitas (contrabando y/o mercados subterráneos). En este caso, y para las tres últimas décadas del siglo pasado, tráfico de armas, insumos químicos para el procesamiento de la coca, la base de coca o la misma cocaína, buscando mercados regionales (países vecinos) y otros puntos de embarque hacia mercados internacionales como se puede observar en la figura 2.

En este sentido, es claro que la circunstancia de la dinámica fronteriza de estos mercados ilegales no es exclusiva del departamento del Putumayo, sino que es un corredor estratégico a lo largo de todas las fronteras nacionales; de hecho, para el año 2016 el Informe oficial de la ONU (UNODC, 2017) establecía que los departamentos de Nariño, Putumayo y Norte de Santander eran los más afectados por el cultivo de la coca, concentrando el 63\% de la producción nacional. Para el caso puntual de la frontera sur del país, la que nos interesa de forma preponderante, vemos que, entre el 2008 y el 2016 (figura 3 ), las hectáreas cultivadas pasaron de 30.106 a 67.956 , con un importante incremento porcentual en el departamento del Putumayo.

Hoy ocurre lo propio con los cultivos de pimienta localizados en el Valle del Guamuez, ${ }^{5}$ cuyo producto se escurre a Ecuador a través de San Miguel, para ser luego comercializada no solo en este país, sino incluso, en la misma Colombia (Bermúdez, 2018); ello, sin mencionar, el contrabando que circula regularmente
${ }^{4}$ Este concepto hace referencia a cómo es posible establecer, en cada coyuntura histórica, la forma en que los actores sociales se organizan y responden a las necesidades puntuales y particulares, pero como producto de un proceso histórico y una posición relativa que en buena medida define dicha respuesta.

5 Implementados, de hecho, como parte de la política de sustitución de cultivos ilícitos.

territarias 45 271

TERRITORIO, VIOLENCIA Y DESASTRES EN COLOMBIA: UN ACERCAMIENTO A LA MEMORIA HISTÓRICA AMBIENTAL 
Figura 2. Rutas de tráfico y comercialización de productos ilícitos en el Putumayo

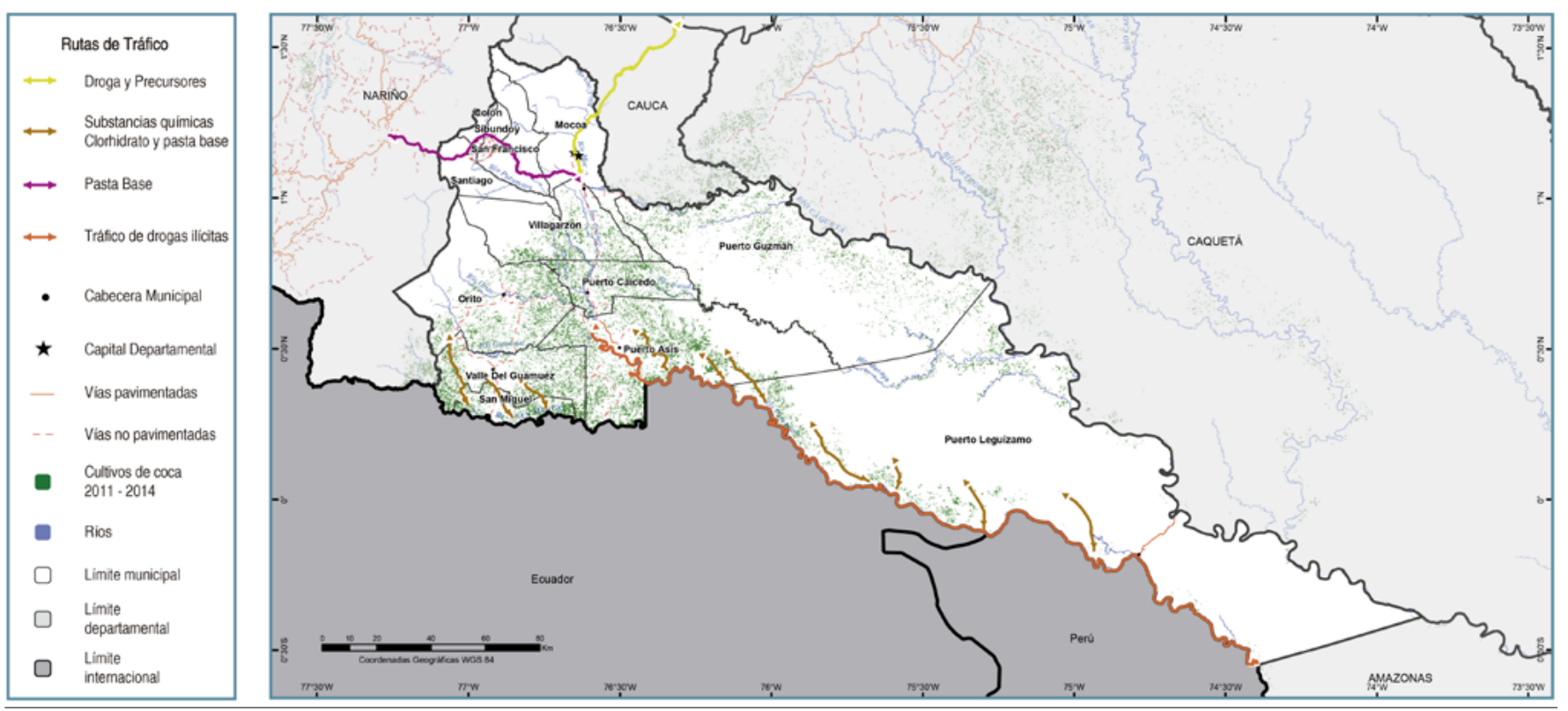

Fuente: UNODC, 2013.

${ }^{6}$ El Ministerio de Agricultura identificó como tipos de despojo implementados en Colombia, los siguientes: La transferencia forzada de dominio, las ventas falsas, la caducidad administrativa, el desplazamiento de propietarios y el desplazamiento de poseedores, ocupantes $y$ tenedores (PNUD, 2009).

\section{territarias 45} 272 por el río, desde Brasil, donde en pequeñas embarcaciones se introduce al país, granos, licores, dulces procesados, aceites, productos de aseo, ropa y calzado (Armada de Colombia, 2018). Es notoria entonces, en los departamentos de Nariño y Amazonas, y en los estados de Ecuador, Perú y Brasil, del otro lado de la frontera, la permanente retroalimentación que se da en la zona por las dinámicas propias del contrabando y que aluden a la condición porosa y al control institucional disperso de la frontera.

De otra parte, la región Amazónica, como prácticamente todo el país, ha sufrido procesos de usurpación y concentración de la tierra a través de la intimidación, los asesinatos y el despojo. ${ }^{6}$ Despojo que está favorecido por la altísima informalidad de la tenencia de la tierra en Colombia y por la carencia de información actualizada que permita legalizar efectivamente su posesión.

Precisamente, el PNUD (2009) encontraba que solo el $18,7 \%$ de la población desplazada registrada en Colombia podría reconocerse como propietaria formal de los predios abandonados; ello da una idea de la magnitud del problema y de la complejidad para reconocer la condición de víctima e implementar los mecanismos de restauración de derechos y restitución de tierras. Según este mismo documento, en esta región los predios abandonados o 
Figura 3. Hectáreas dedicadas al cultivo de la coca en la frontera sur de Colombia, 2008-2016

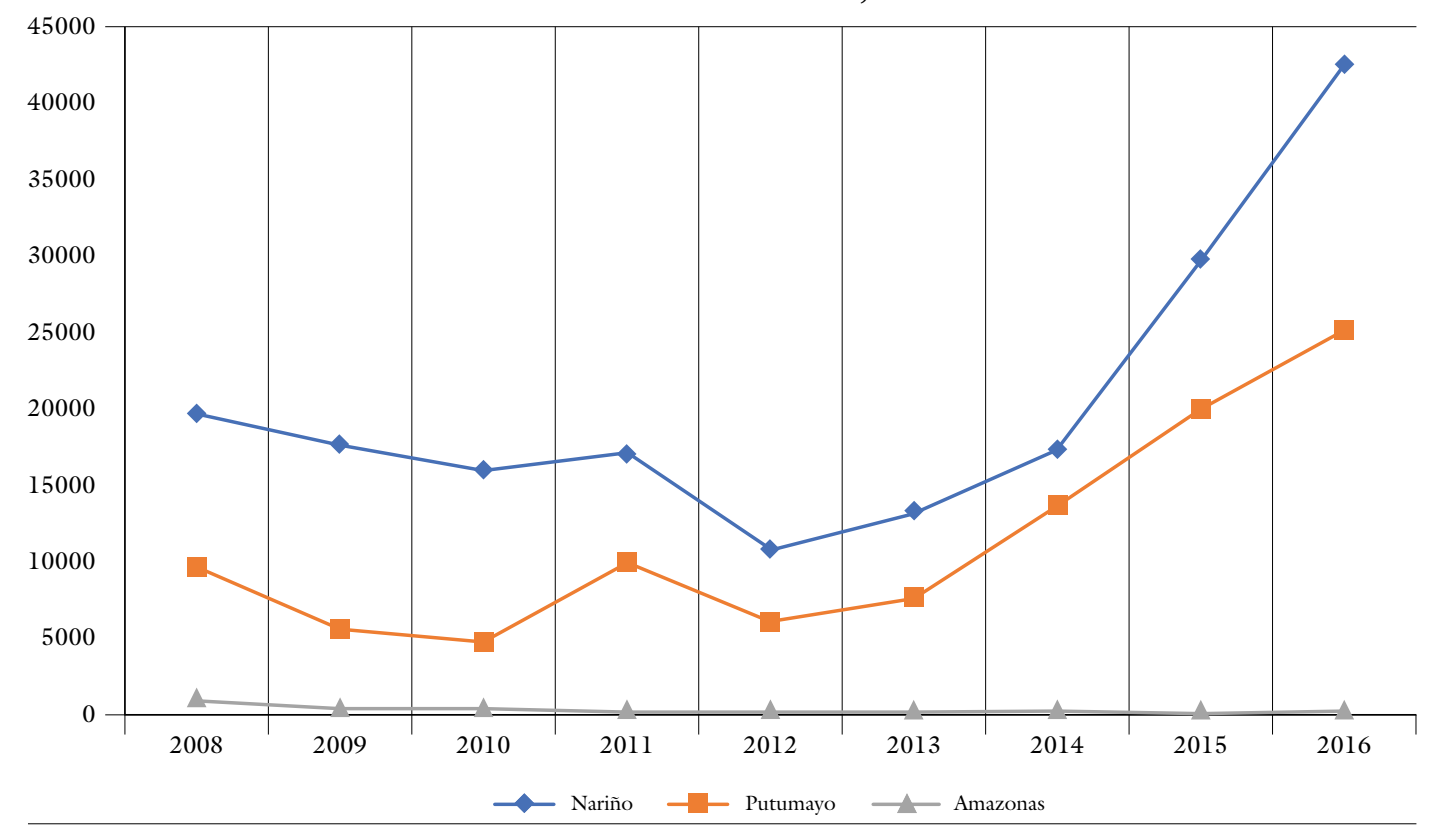

Fuente: UNODC, 2017.

despojados son los más extensos del país (el $42,2 \%$ de ellos son superiores a 15 has.) y el departamento del Putumayo está entre los más afectados. Allí los actores más representativos de estos hechos son los grupos armados ilegales, guerrilla, paramilitares y narcotraficantes, y las áreas más afectadas son las de las comunidades indígenas. Convergente con ello, la construcción de la carretera Mocoa-Puerto Asís y el ingreso de las petroleras Texas Petroleum Company y Gulf Oil Company, a las que el gobierno les entregó una concesión por 30 años para la explotación del crudo en Orito, han generado importantes despojos en las comunidades indígenas de

TERRITORIO, VIOLENCIA Y DESASTRES EN COLOMBIA: UN ACERCAMIENTO A LA MEMORIA HISTÓRICA AMBIENTAL la zona, que ya solo disponen del $26 \%$ de los territorios reconocidos a ellos por el INCORA a comienzos de los años setenta (PNUD, 2009). Adicionalmente, la minería ilegal de oro aluvial en el río Cocayá, en el municipio de Puerto Caicedo, y en varias quebradas de los municipios de Puerto Guzmán, Puerto Asís y Villagarzón, como de socavón en la vereda Buenos Aires de Mocoa (Conexión Putumayo, 2019), entre muchos otros, expresa otra causa de conflicto en la zona, bajo el control de antiguos y nuevos agentes territoriales, que exigen, por tanto, nuevas rutas, contactos y mercados ilegales para acceder y controlar.

territarias 45 273 
7 El Índice de Pobreza Multidimensional (IPM) se construye con base en cinco dimensiones: las condiciones educativas del hogar, las condiciones de la niñez y la juventud, la salud, el trabajo y el acceso a los servicios públicos domiciliarios y las condiciones de la vivienda. Estas cinco dimensiones involucran 15 indicadores y son considerados pobres, los hogares que tengan privación en por lo menos el 33\% de los indicadores (DANE, 2017).

\section{territarias 45} 274
Narcotráfico, contrabando, minería ilegal, megaproyectos y débil presencia institucional, propician la emergencia de actores armados y acciones ilícitas que garantizan el control y la regulación del territorio (incluida la tierra) y sus actividades, en función de intereses y proyectos particulares, produciéndose un clima favorable para la presencia y evolución de conflictos violentos que afectan de forma, más o menos generalizada, a las poblaciones más vulnerables. Puntualmente, guerrillas y paramilitares han hecho presencia en la zona desde las décadas de los 80 y 90 , respectivamente. Los frentes 32,48 y 49 de las FarC y el Bloque Sur de Putumayo, del grupo paramilitar, han ejercido, en momentos y áreas particulares, control territorial. Ello magnificó en puntos y tiempos específicos el conflicto armado y los hechos violentos que azotaron de forma significativa el departamento.

Estas condiciones se ven, en mayor o menor medida reflejadas, en los indicadores de bienestar social del departamento.

Al revisar el Índice de Desarrollo Humano (IDH) para Colombia se encuentra que, entre el 2000 y el 2010 este aumentó en seis puntos, pasando de 0,78 a 0,84 ; cifras que muestran mejoría en las condiciones de bienestar de la población para la primera década de este siglo, ello acorde con la tendencia mundial. Sin embargo, estas cifras contrastan con la alta heterogeneidad que se vive al interior del país; en tanto Bogotá aumentó su IDH en este período en seis puntos (pasando de 0,844 a 0,904), el mayor en el país, la Guajira tan solo lo hizo en medio punto, mientras que Putumayo pasó de 0,696 en el año 2000 a 0,759 en el 2010 (DANE, 2017). En la tabla 1 se aprecia que, para todos los años de este decenio el Putumayo ha estado bastante por debajo de la media nacional, creciendo también menos que el promedio del país y que, al 2010, su IDH es inferior a la media nacional de inicios de siglo y todavía mucho menor al de Bogotá, Valle del Cauca, Antioquia o los departamentos de Casanare, Santander, Boyacá o Meta, más cercanos en sus características, al del Putumayo. Es decir, sus condiciones combinadas de vida (ingresos económicos, esperanza de vida $\mathrm{y}$ tasa de escolaridad) están aún lejanas de las que gran parte del país tenía hace más de una década.

Frente a las cifras de pobreza multidimensional, ${ }^{7}$ se aprecia que el departamento tiene una incidencia de $76,3 \%$ de ella (figura 4), cifra muy superior a la observada a nivel nacional, del $49 \%$; esto establece que aproximadamente el $80 \%$ de la población del Putumayo no tiene unas condiciones materiales, educativas, laborales, de salubridad y acceso a la salud y bienestar en general, que los favorezca, antes que perjudicarlos. Esta situación es propia tanto de las áreas urbanas como rurales, puesto que las estadísticas muestran que ambas son superiores al promedio nacional; $65 \%$ versus $39 \%$ y $88 \%$ versus $80 \%$, respectivamente. Contrasta la gran distancia relativa existente en las áreas 
Tabla 1. Índice de Desarrollo Humano (IDH) por departamentos 2000-2010

\begin{tabular}{|c|c|c|c|c|c|c|c|c|c|c|c|}
\hline \multicolumn{12}{|c|}{ Índice de Desarrollo Humano por departamentos 2000-2010 } \\
\hline Departamento & 2000 & 2001 & 2002 & 2003 & 2004 & 2005 & 2006 & 2007 & 2008 & 2009 & 2010 \\
\hline Antioquia & 0,781 & 0,781 & 0,786 & 0,792 & 0,800 & 0,807 & 0,806 & 0,817 & 0,830 & 0,838 & 0,849 \\
\hline Arauca & 0,785 & 0,763 & 0,769 & 0,780 & 0,787 & 0,796 & 0,789 & 0,792 & 0,798 & 0,799 & 0,804 \\
\hline Atlántico & 0,786 & 0,784 & 0,786 & 0,791 & 0,797 & 0,801 & 0,797 & 0,806 & 0,817 & 0,824 & 0,835 \\
\hline Bogotá, D.C. & 0,844 & 0,843 & 0,848 & 0,853 & 0,862 & 0,870 & 0,869 & 0,881 & 0,892 & 0,897 & 0,904 \\
\hline Bolívar & 0,759 & 0,761 & 0,764 & 0,778 & 0,783 & 0,787 & 0,783 & 0,795 & 0,805 & 0,812 & 0,823 \\
\hline Boyacá & 0,774 & 0,774 & 0,778 & 0,783 & 0,789 & 0,798 & 0,798 & 0,811 & 0,824 & 0,828 & 0,842 \\
\hline Caldas & 0,758 & 0,763 & 0,771 & 0,776 & 0,782 & 0,789 & 0,788 & 0,797 & 0,809 & 0,822 & 0,828 \\
\hline Caquetá & 0,706 & 0,707 & 0,707 & 0,717 & 0,719 & 0,723 & 0,718 & 0,725 & 0,735 & 0,769 & 0,752 \\
\hline Casanare & 0,848 & 0,834 & 0,835 & 0,848 & 0,854 & 0,859 & 0,855 & 0,855 & 0,861 & 0,859 & 0,867 \\
\hline Cauca & 0,712 & 0,714 & 0,721 & 0,726 & 0,735 & 0,742 & 0,739 & 0,749 & 0,761 & 0,760 & 0,782 \\
\hline Cesar & 0,715 & 0,723 & 0,731 & 0,745 & 0,761 & 0,770 & 0,771 & 0,778 & 0,791 & 0,788 & 0,810 \\
\hline Chocó & 0,660 & 0,659 & 0,659 & 0,672 & 0,684 & 0,687 & 0,686 & 0,696 & 0,708 & 0,744 & 0,731 \\
\hline Córdoba & 0,726 & 0,724 & 0,730 & 0,739 & 0,748 & 0,751 & 0,752 & 0,765 & 0,775 & 0,757 & 0,798 \\
\hline Cundinamarca & 0,783 & 0,786 & 0,788 & 0,796 & 0,799 & 0,803 & 0,799 & 0,808 & 0,821 & 0,824 & 0,837 \\
\hline Grupo Amazonía & 0,675 & 0,683 & 0,693 & 0,699 & 0,714 & 0,730 & 0,729 & 0,741 & 0,751 & 0,784 & 0,768 \\
\hline Huila & 0,748 & 0,745 & 0,751 & 0,760 & 0,769 & 0,774 & 0,773 & 0,780 & 0,791 & 0,779 & 0,807 \\
\hline La Guajira & 0,686 & 0,693 & 0,683 & 0,693 & 0,700 & 0,705 & 0,694 & 0,689 & 0,690 & 0,688 & 0,691 \\
\hline Magdalena & 0,717 & 0,720 & 0,726 & 0,731 & 0,737 & 0,744 & 0,742 & 0,752 & 0,764 & 0,772 & 0,785 \\
\hline Meta & 0,770 & 0,767 & 0,770 & 0,776 & 0,781 & 0,785 & 0,783 & 0,791 & 0,802 & 0,810 & 0,822 \\
\hline Nariño & 0,713 & 0,715 & 0,722 & 0,730 & 0,738 & 0,742 & 0,741 & 0,746 & 0,756 & 0,762 & 0,773 \\
\hline Norte de Santander & 0,733 & 0,732 & 0,737 & 0,740 & 0,746 & 0,748 & 0,749 & 0,760 & 0,775 & 0,784 & 0,796 \\
\hline Putumayo & 0,696 & 0,697 & 0,704 & 0,710 & 0,721 & 0,727 & 0,727 & 0,735 & 0,745 & 0,750 & 0,759 \\
\hline Quindío & 0,748 & 0,751 & 0,755 & 0,759 & 0,766 & 0,780 & 0,785 & 0,798 & 0,813 & 0,821 & 0,832 \\
\hline Risaralda & 0,752 & 0,752 & 0,757 & 0,766 & 0,778 & 0,788 & 0,790 & 0,803 & 0,818 & 0,828 & 0,839 \\
\hline
\end{tabular}

TERRITORIO, VIOLENCIA Y DESASTRES EN COLOMBIA: UN ACERCAMIENTO A LA MEMORIA HISTÓRICA AMBIENTAL 


\begin{tabular}{|l|c|c|c|c|c|c|c|c|c|c|c|}
\hline \multicolumn{10}{|c|}{ Índice de Desarrollo Humano por departamentos 2000-2010 } \\
\hline \multicolumn{1}{|c|}{ Departamento } & $\mathbf{2 0 0 0}$ & $\mathbf{2 0 0 1}$ & $\mathbf{2 0 0 2}$ & $\mathbf{2 0 0 3}$ & $\mathbf{2 0 0 4}$ & $\mathbf{2 0 0 5}$ & $\mathbf{2 0 0 6}$ & $\mathbf{2 0 0 7}$ & $\mathbf{2 0 0 8}$ & $\mathbf{2 0 0 9}$ & $\mathbf{2 0 1 0}$ \\
\hline San Andrés & 0,826 & 0,825 & 0,831 & 0,831 & 0,835 & 0,832 & 0,824 & 0,828 & 0,832 & 0,831 & 0,834 \\
\hline Santander & 0,794 & 0,796 & 0,801 & 0,808 & 0,818 & 0,827 & 0,827 & 0,842 & 0,856 & 0,866 & 0,879 \\
\hline Sucre & 0,724 & 0,725 & 0,724 & 0,727 & 0,735 & 0,739 & 0,737 & 0,747 & 0,758 & 0,765 & 0,775 \\
\hline Tolima & 0,739 & 0,740 & 0,745 & 0,750 & 0,760 & 0,764 & 0,764 & 0,773 & 0,785 & 0,793 & 0,804 \\
\hline Valle del Cauca & 0,801 & 0,800 & 0,803 & 0,806 & 0,813 & 0,819 & 0,820 & 0,832 & 0,845 & 0,852 & 0,861 \\
\hline Total Nacional & 0,780 & 0,780 & 0,784 & 0,791 & 0,798 & 0,804 & 0,803 & 0,814 & 0,826 & 0,831 & 0,840 \\
\hline
\end{tabular}

Fuente: DANE, 2017.

urbanas, con la cercanía para las rurales, que muestra, en general para el país, la concentración de oportunidades en las primeras en desmedro de las segundas y, por ende, el significativo retraso de las condiciones urbanas en el departamento.

En relación con el comportamiento espacial del IPM al interior del departamento (figura 5), se tiene que, los mayores índices de pobreza se encuentran en los municipios de Puerto Leguízamo, Puerto Guzmán y Villa Garzón, casi alineados los tres a lo largo del río Caquetá y en el de Valle del Gauméz, limítrofe con el Ecuador.

En cuanto a las variables que componen el índice, el departamento, en comparación con el país, presenta rezago en todas ellas (figura 6), a excepción de la de pisos inadecuados, validando esto el significativo retraso que sufre la población, expresado líneas atrás, y la dimensión y complejidad de la intervención a realizar para modificar esta situación.
La cobertura de servicios públicos no es muy diferente, todo el departamento presenta una relativamente baja cobertura de ellos; en acueducto tiene el $44 \%$, en alcantarillado un $48 \%$ y un $67 \%$ en energía eléctrica (DANE, 2005), habiendo también profundas diferencias entre los municipios (tabla 2). Asimismo, el índice de necesidades básicas insatisfechas (NBI) en el departamento es del 36\%, superior al nacional que está en $28 \%$ y la proporción de personas en miseria es ligeramente superior al promedio nacional, $8,8 \%$ frente a $8,1 \%$ (DANE, 2005).

El Atlas de la Distribución de la Propiedad Rural en Colombia, realizado bajo la dirección del IGAC, estableció, con base en las áreas de los terrenos en poder de cada uno de los propietarios rurales en Colombia, un indicador de Gini de tierras; "si estos resultados se comparan con los de otros países, se concluye que Colombia registra una de las más altas 
Figura 4. Porcentaje de personas multidimensionalmente pobres (incidencia)

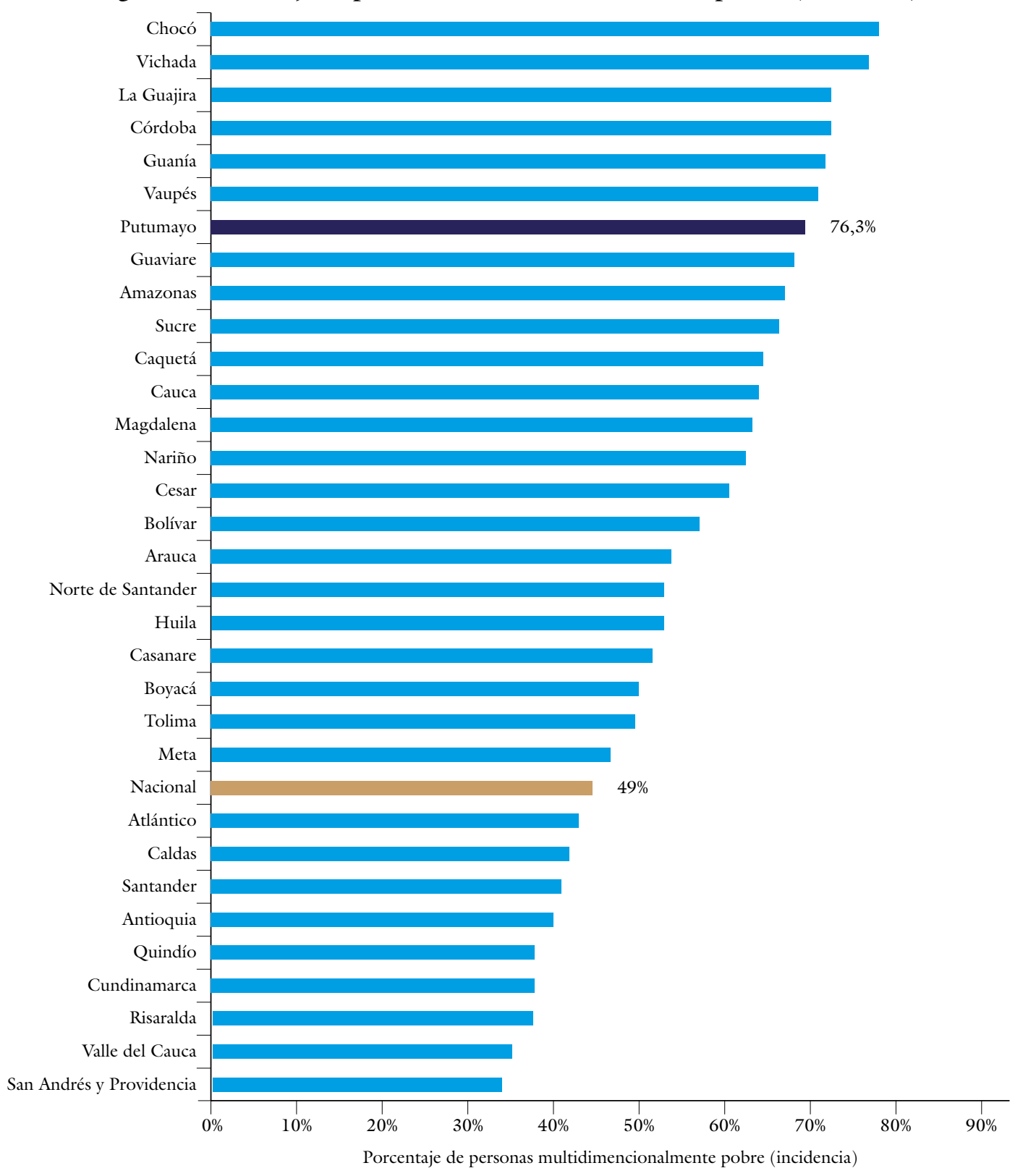

Fuente: tomado de Martínez y Delgado, 2017. 
Figura 5. Índice de pobreza multidimensional en los municipios del Putumayo, 2005
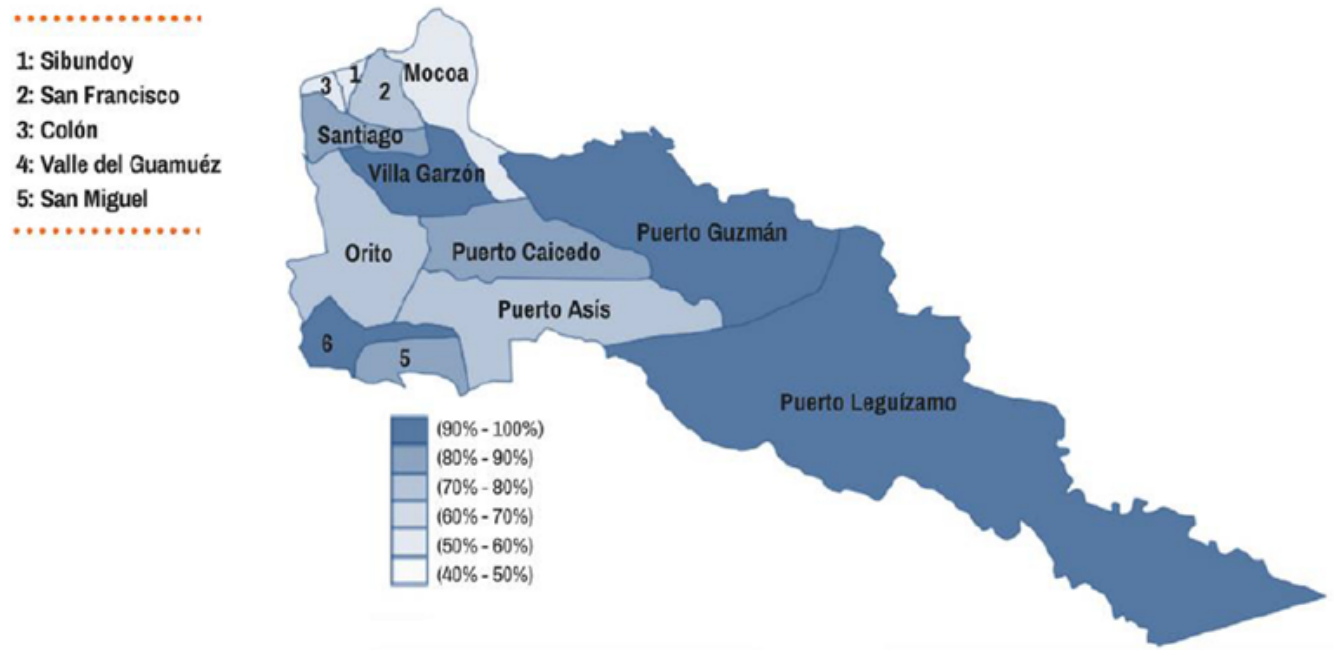

Fuente: tomado de Martínez y Delgado, 2017.

Figura 6. Incidencia de variables del IPM en el Putumayo y el país, 2005

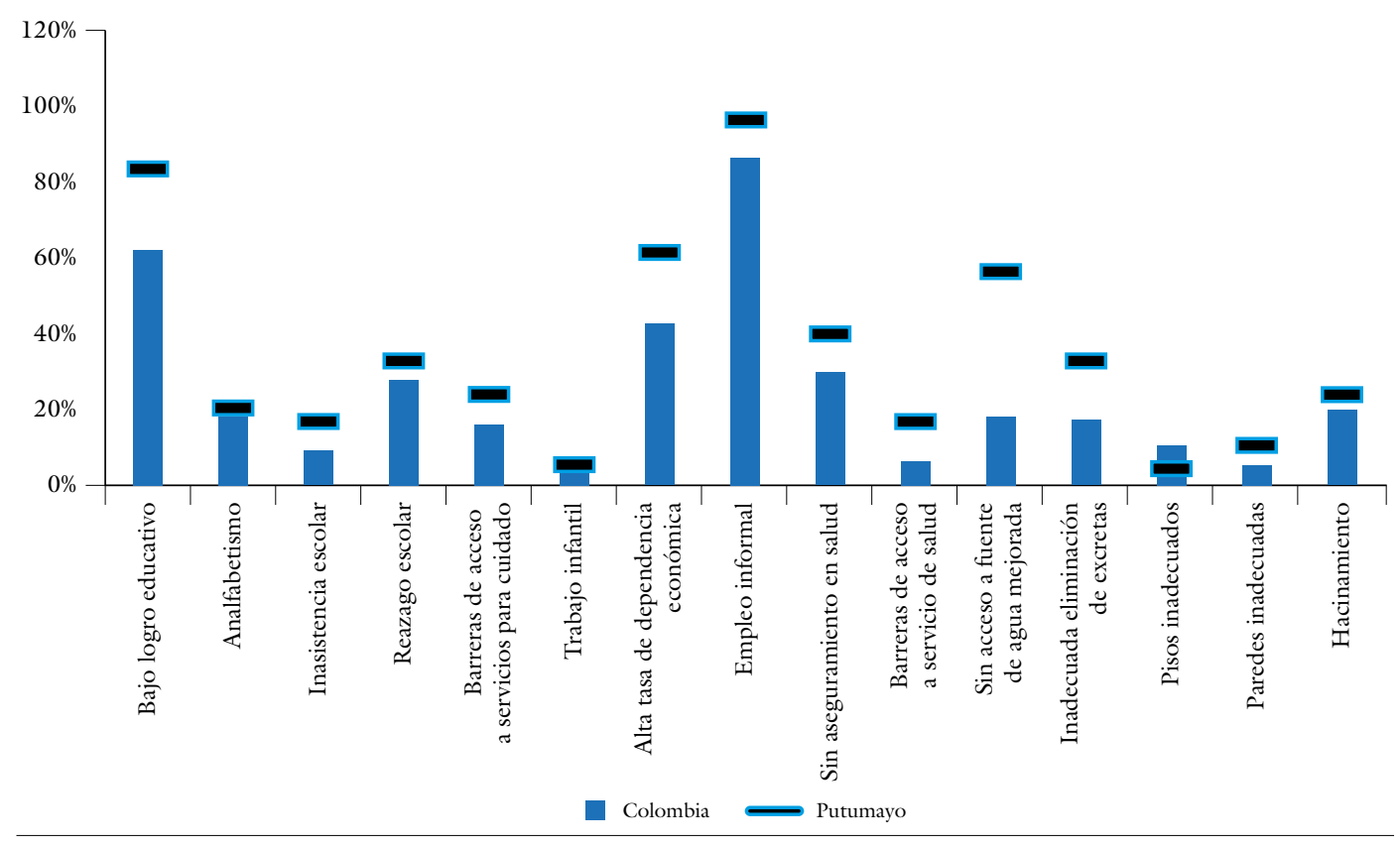

Fuente: tomado de Martínez y Delgado, 2017. 
Tabla 2. Servicios públicos en el Putumayo

\begin{tabular}{|l|c|c|c|}
\hline Municipio & $\begin{array}{c}\text { Acueducto } \\
(\mathbf{\%})\end{array}$ & $\begin{array}{c}\text { Alcantarillado } \\
\mathbf{( \% )}\end{array}$ & $\begin{array}{c}\text { Energía } \\
\mathbf{( \% )}\end{array}$ \\
\hline Mocoa & 85,18 & 69,37 & 90,77 \\
\hline Colón & 92,68 & 85,74 & 95,78 \\
\hline Leguízamo & 69,22 & 65,53 & 77,63 \\
\hline Orito & 29,62 & 28,73 & 50,16 \\
\hline Puerto Asís & 19,53 & 53,08 & 64,93 \\
\hline $\begin{array}{l}\text { Puerto } \\
\text { Caicedo }\end{array}$ & 27,35 & 34,64 & 48,4 \\
\hline $\begin{array}{l}\text { Puerto } \\
\text { Guzmán }\end{array}$ & 74,76 & 49,84 & 71,95 \\
\hline $\begin{array}{l}\text { San } \\
\text { Francisco }\end{array}$ & 88.53 & 62,01 & 92,1 \\
\hline San Miguel & 0,34 & 20,78 & 35,23 \\
\hline Santiago & 90,83 & 49,9 & 88,2 \\
\hline Sibundoy & 94,79 & 73,93 & 95,79 \\
\hline $\begin{array}{l}\text { Valle del } \\
\text { Guamuez }\end{array}$ & 19,58 & 34,76 & 54,68 \\
\hline Villagarzón & 60,66 & 48,49 & 73,42 \\
\hline Total & 44,04 & 47,84 & 66,68 \\
\hline Sente: & & & \\
\hline
\end{tabular}

Fuente: DANE, 2005.

desigualdades en la propiedad rural en América Latina y el mundo" (PNUD, 2011, p. 197). En el caso del Putumayo, este es muy alto $(0,72)$ e indica la gran inequidad en la distribución de tierras en el departamento (IGAC, 2012); las razones que sustentan ello son las mismas que para el país:

TERRITORIO, VIOLENCIA Y DESASTRES EN COLOMBIA: UN ACERCAMIENTO A LA MEMORIA HISTÓRICA AMBIENTAL
Consecuencia de un proceso histórico, de las políticas públicas, de la operación de las fuerzas del mercado, del narcotráfico y la actuación de grupos armados por fuera de la ley, así como de la cultura de rápido enriquecimiento, y la avidez de renta. (PNUD, 2011, p. 197)

Las cifras económicas tienen la misma tendencia, mientras que para el 2015 Bogotá aportaba el 25\% del PIB nacional, el departamento de Putumayo contribuyó con menos del 1\% (0,6\%, según el DNP, 2015). Para esa misma fecha y según la misma fuente, la tasa de desempleo era de $10,7 \%$.

De otra parte, con el Acuerdo de Paz firmado por el gobierno colombiano y las bana, se generó un vacío de poder y territorial, que fue aprovechado por otros agentes presentes en la zona o por aquellos que no se sumaron al acuerdo, y que, bajo una cruenta disputa y recomposición territorial, están reconfigurando agentes, actividades y controles. En contraste, las expectativas y realidades de este acuerdo han resignificado, visibilizado y empoderado a las comunidades como agentes territoriales y sujetos de derechos y de necesidades no satisfechas. Es así como la restitución de tierras se ha convertido en uno de los ejes centrales de sus demandas y una acción obligada del Estado en ese proceso de justicia y reparación de las víctimas; no obstante, esto ha centrado el actuar de los violentos en ellos. FARC, en septiembre de 2016 en La Ha- 
${ }^{8}$ Quienes estén interesados en hacer un seguimiento detallado del fenómeno de desplazamiento en Putumayo pueden revisar el trabajo de Sánchez (2012).

${ }^{9}$ Desafortunadamente, el registro oficial de desplazados nace con la Ley 387 de 1997, por tanto, antes de esta fecha se tienen estadisticas municipales aisladas y fragmentadas que no permiten hacerse de una clara idea del problema. Igualmente, los requisitos que establece la ley para la categoría de desplazado dejan por fuera a aquellas personas que resulten afectadas por operativos antinarcóticos, erradicación de cultivos ilicitos y fumigaciones aéreas, que tengan que migrar forzosamente (destierro) y por ello fácilmente se puede hablar de un subregistro; esto sin mencionar aquellas personas que prefieren callar su condición, para no ser estigmatizados como desplazados.

\section{territarias 45} 280
Una nota del periódico El Espectador del 21 de diciembre de 2017 refería que, a esa fecha, la Oficina en Colombia del Alto Comisionado de las Naciones Unidas para los Derechos Humanos tenía registrados 105 homicidios de defensores de derechos humanos, así, "73 asesinatos contra líderes y lideresas, 18 asesinatos de miembros de movimientos sociales y políticos y 14 víctimas durante movilizaciones sociales. Los crímenes fueron perpetrados por sicarios en un 59\%" (Ávila, 2017). Acotaba también este documento que, de acuerdo con la Unidad de Víctimas, en lo corrido de ese 2017 se habían registrado 1.181 desplazamientos forzados en el Putumayo; y sentenciaba finalmente:

La palabra víctima está escrita en casi toda la población putumayense. Cada habitante tiene algún familiar, amigo o vecino que fue asesinado, desplazado o amenazado por grupos armados. Según la Unidad para las Víctimas, el $51 \%$ de la población, cerca de 180.000 personas de 350.000 habitantes, son víctimas del conflicto. (Ávila, 2017)

Esto evidencia que no necesariamente las condiciones territoriales en el departamento cambiaron drásticamente después del acuerdo del 2016 y que los conflictos y la violencia territorial tienen una compleja génesis, más allá de la presencia de la antigua guerrilla de la FARC en la zona.

En fin, no es necesario mostrar más indicadores que evidencien, tanto la alta vulnerabilidad socioeconómica y política de la población rural del departamento (que obviamente lleva consigo e incrementa incluso al moverse a otras zonas), como los factores expulsores del campo putumayense, que arrojan a la población hacia su cabecera urbana. De hecho, en las últimas décadas el departamento ha visto un dramático crecimiento del número de habitantes. Precisamente, Putumayo experimentó un crecimiento poblacional por encima del nacional, entre $1985 \mathrm{y}$ 2005; en el período 1985-1993, la población creció un $22 \%$, incremento a su vez sustentado en un aumento del 36\%, de la población urbana. Durante el periodo de 1993 a 2005, continuó el crecimiento acelerado de la población urbana, mientras que la población rural presentó una baja tasa de crecimiento $(4 \%)$. Y si se compara el total de la población del municipio de Mocoa reportada en el censo nacional del 2005 de 36.185 habitantes, con el total de la población registrada en el Sistema de Información de Población Desplazada (SIPOD) a 2005, de 14.679 personas, tenemos que este grupo de población corresponde en Mocoa a un 41\% de la población. Este dato evidencia el peso significativo que tiene este fenómeno del desplazamiento en el comportamiento demográfico y, por ende, en el urbano en la capital putumayense. ${ }^{8}$

Y es que el arribo de población desplazada tiene ya un comportamiento histórico en la ciudad; el SIPOD tiene un registro, entre 1998 y 2008 , para Mocoa, de 20.520 personas $^{9}$ (figura 7 ); 


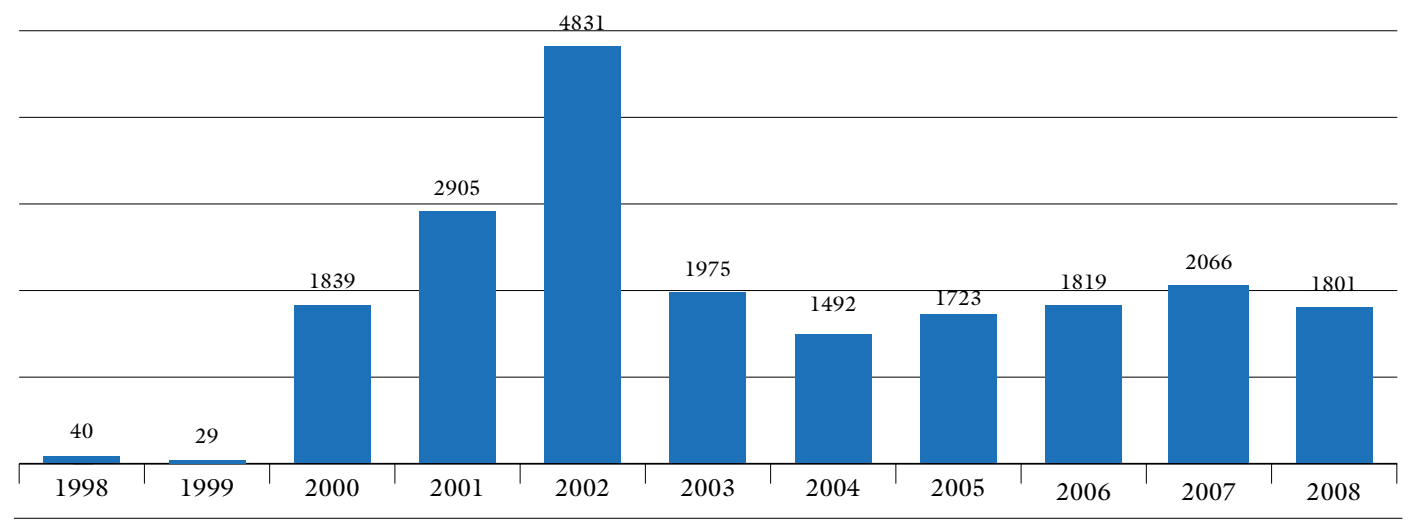

Fuente: tomado de Sánchez (2012).

el bajísimo número de registros en los dos primeros años se debe al inició de la implementación del sistema de registro SUR (antecesor del SIPOD). Ya, en el 2000, el sistema entró en pleno funcionamiento y las cifras muestran la dramática situación; ese año fueron registradas más de 1.800 personas, manteniéndose la cifra en ascenso, hasta el pico más alto registrado en 2002 , con 4.831 personas/año. Luego hubo un descenso hasta el valor más bajo, pero nada despreciable de 1.492 personas en el 2004. Nuevamente de forma lenta fue subiendo hasta presentar una línea relativamente estable en 2008 , con una cifra de 1.801 personas ese año (Sánchez, 2012).

Esta población desplazada de los diversos municipios del Putumayo y de otros departamentos vecinos, se localiza, de forma preponderante, en asentamientos humanos irregulares, en lugares con baja capacidad de acogida y en condiciones de inseguridad e insostenibilidad natural; tal es el caso de los barrios San Miguel, Los Laureles y San Fernando, ubicados en áreas de influencia de la quebrada $\mathrm{La}$ Taruca y el río Sangoyaco, que fueron precisamente los más afectados la madrugada del 1 de abril de 2017. Ello muestra el círculo vicioso establecido entre violencia territorial-desplazamiento-ocupación irregular-exposición-vulnerabilidad-desastre-degradación ambiental- vulnerabilidad-violencia territorial.

Al retomar las preguntas de principio de este numeral, puede decirse entonces, que si bien el evento que afectó la ciudad tiene causas naturales, estas se ven alteradas de forma significativa por intervenciones antrópicas; la deforestación de las cuencas de los ríos Taruca, 
Mulato y Sancoyaco, y de sus quebradas tributarias, hecho reconocido ampliamente en la zona, aumentó la escorrentía, magnificando su capacidad de arrastre y devastación, al tiempo que, la violencia y el despojo territorial en el sur del país, y en especial en el departamento, propició la ocupación urbana en Mocoa (invasiones) en zonas expuestas a eventos torrenciales, como es la ya referida situación de estos barrios. En síntesis, se expusieron a lo largo de este numeral, circunstancias sociales, históricas y geopolíticas particulares que propician condiciones expulsoras (desplazamiento y migración) de las zonas rurales del departamento, a la vez que presiones urbanas artificiales (no en función de sus propias dinámicas) en Mocoa, principal centro poblado en la zona. En consecuencia, la violencia rural que ha sufrido y sufre aún el departamento del Putumayo propicia que, ciertos indicadores sociales de su capital, generen un estado de cosas favorable para la ocurrencia potencial de desastres; en otras palabras, la vulnerabilidad social de las comunidades rurales expulsadas por los violentos de sus propios territorios, se suma a la vulnerabilidad física, institucional y económica que encuentran en la ciudad de Mocoa, configurando complejos sistemas de vulnerabilidades que, en un círculo vicioso, los exponen de forma progresiva y selectiva ante eventos potencialmente destructivos, que afectan de forma considerable también a la naturaleza, que demanda ciclos de tiempo largos para su restauración y que nadie ve, le importa o quiere mencionar.

Teniendo ello en mente es posible proponer, ahora, algunas ideas alrededor de la MHA como intención y ojalá como realidad tangible en la sociedad colombiana.

\section{Por una memoria histórica ambiental}

La naturaleza como sujeto de derechos se reconoce en Colombia claramente a partir de 2016. En ese año, comunidades negras del Chocó interpusieron una tutela ante la Corte Constitucional con el objeto de detener la explotación forestal ilegal y la extracción ilegal de minerales, en la cuenca del río Atrato, cuyas consecuencias sobre el río y las comunidades son desastrosas e irreversibles. La corte reconoció al río como sujeto de derechos, basada en el reconocimiento de derechos bioculturales de las comunidades, es decir, los derechos que tienen estas de administrar autónomamente sus territorios de acuerdo con sus propias leyes, historia y costumbres. No se trata en sí de nuevos derechos, sino de la integración de los que ya tienen las comunidades étnicas a su cultura y a la protección del medio ambiente que habitan, con base en la relación intrínseca que existe entre ambas, reconociendo que, como territorio, el bienestar del río está directamente vinculado con el bienestar de las comunidades.

Luego en abril de 2018, la Corte Suprema, retomando el precedente 
mencionado, reconoce también a la Amazonía como entidad sujeta de derechos, fallando favorablemente a una tutela presentada por 25 jóvenes de diferentes ciudades del país. Esta buscaba garantizar los derechos fundamentales, amenazados por la deforestación que induce un aumento de las emisiones de gases efecto invernadero, principal causa del cambio climático. Frente a ello, la corte expresó:

puede predicarse, los derechos fundamentales de la vida, salud el mínimo vital, la libertad y la dignidad humana están ligados sustancialmente y determinados por el entorno y el ecosistema. Sin ambiente sano los sujetos de derecho y los seres sintientes en general no podremos sobrevivir, ni mucho menos resguardar esos derechos, para nuestros hijos ni para las generaciones venideras. Tampoco podrá garantizarse la existencia de la familia, de la sociedad o del propio Estado. (Corte Suprema de Justicia, 2018, p. 13)

La Corte basó su decisión sobre los principios de solidaridad y equidad intergeneracional que sustentan los derechos ambientales de las generaciones futuras, así:

Los derechos ambientales de las futuras generaciones se cimentan en el (i) deber ético de la solidaridad de la especie y (ii) en el valor intrínseco de la naturaleza.

El primero, se explica por cuanto los bienes naturales se comparten por todos los habitantes del Planeta Tierra, y por los descendientes o generaciones venideras que aún no los tienen materialmente pero que son tributarios, destinatarios y titulares de ellos, siendo aquéllos, sin embargo, contradictoriamente, cada vez más insuficientes y limitados. De tal forma que, sin la existencia actual de un criterio equitativo y prudente de consumo, la especie humana podrá verse comprometida en el futuro por la escasez de recursos imprescindibles para la vida. De esta forma, solidaridad y ambientalismo se relacionan hasta convertirse en lo mismo.

Así las cosas, la fundamentación de la obligación de solidaridad humana con la naturaleza constituye el contenido esencial de los verdaderos valores que diariamente le facilitan la vida, tanto en su dimensión presente como futura. Esta idea, instaura una ética dinámica y material de los valores ambientales, ajustada y compatible con [...] las necesidades de conservación de la naturaleza en el sentido más favorable para mantener por siempre la vida de los seres humanos $[\ldots]$.

El segundo; trasciende de la perspectiva antropocéntrica, y se enfoca en criterio ecocéntrico-antrópico, el cual sitúa al ser humano a la par del entorno ecosistémico, cuya finalidad es evitar el trato prepotente, displicente e irresponsable del recurso ambiental, y de todo su contexto, para satisfacer fines materialistas coma sin ningún respeto proteccionista o conservacionista. (Corte Suprema de Justicia, 2018, pp. 19-21) 
${ }^{10}$ La Constitución de Ecuador dedicó todo un capitulo al respeto $y$ derechos de la naturaleza; con base en ello las cortes ecuatorianas han resuelto más de 25 casos favoreciéndola.

${ }^{11}$ En 2014 el Estado de Guerrero reconoció, en una modificación a su Constitución, el deber de garantizar y proteger los derechos de la naturaleza. La Ciudad de México, en su nueva Constitución de 2017, incluyó en su articulo 18 el reconocimiento de la naturaleza como ente colectivo sujeto de derechos.

${ }^{12}$ El río Whanganui fue reconocido como sujeto de derechos a través de una ley aprobada por el parlamento neozelandés.

${ }^{13}$ Bolivia expidió en 2012 la "Ley Marco de la Madre Tierra y desarrollo integral para vivir bien", que establece los "derechos de la madre tierra como sujeto colectivo de interés público”.

\section{territarias 45}

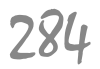

Como vemos, la Corte enfatizó en que el principio de solidaridad conlleva necesariamente un autorreconocimiento del ser humano como parte de la naturaleza, lo que implica, a su vez, reconocer el valor intrínseco que ella tiene; en otras palabras, más allá de la vida que existe y se reconoce como parte integral de la Amazonía (Eslava, 2019), se reconoce que ella es titular de protección, mantenimiento, conservación y restauración, de parte del hombre, por aquello que implica en sí, para las comunidades existentes en ella y la sociedad en general. Igualmente, se reconoce su valor e importancia para las generaciones futuras y la responsabilidad de las actuales para con ellas.

Estos dos casos y otros similares presentados en Ecuador, ${ }^{10}$ México, ${ }^{11}$ Nueva Zelanda, ${ }^{12}$ o Bolivia, ${ }^{13}$ por mencionar solo algunos ejemplos, muestran que es necesario reconocer el papel que ha jugado, juega y jugará la especie humana y la sociedad que ha configurado, en la transgresión, cada vez más agresiva y casi ya de forma irreversible, en el balance y en la capacidad de recuperación de los diversos ecosistemas en el planeta. Se reconoce entonces, que la integridad de la naturaleza puede verse afectada de forma independiente a los daños sobre los seres humanos y ello en sí mismo implica posturas éticas a asumir.

En relación directa con conflictos armados y la naturaleza como víctima, el Protocolo I adicional a los Convenios de Ginebra prohíbe "el empleo de métodos o medios de hacer la guerra que hayan sido concebidos para causar, o de los que quepa prever que causen, daños extensos, duraderos y graves al medio ambiente natural" (1977, numeral 3 art. 35), y "los ataques contra el medio ambiente natural como represalias" (art. 55). Si bien ellos son aplicables a conflictos internacionales, establecen pautas importantes para valoración de situaciones nacionales.

En general, y para el caso colombiano en particular, la naturaleza ha sido víctima silente, pero sistemática del conflicto (armado y territorial), y olvidada en los momentos consecuentes a este. Ella ha recibido el impacto directo de los fusiles y la voladura de los oleoductos, pero también, los químicos usados en la minería, agricultura o fumigaciones contra cultivos ilegales; la deforestación para ampliar la frontera agrícola; la contaminación de fuentes hídricas por desechos urbanos; o la ocupación descontrolada de asentamientos humanos, que degradan o alteran irreversiblemente procesos, dinámicas y propiedades naturales; por mencionar solamente algunos de los más significativos. Paradójicamente, en algunas zonas y como parte del control territorial inherente a la dinámica del mismo conflicto armado, algunas zonas de la Amazonia colombiana fueron preservadas por aislamiento o exclusión a grandes proyectos de inversión.

No obstante, en esta última década se ha empezado a reconocer que ella, per se, es víctima, pero también, en su condición 
de territorio, como parte constitutiva de la cosmovisión, historia, tradición, base material y el vínculo social y colectivo de los pueblos ancestrales en el Pacífico, Amazonas o la Orinoquia, por ejemplo. Efectivamente, antes de estas sentencias de la Corte Suprema de Justicia, a través del Decreto Ley 4633 del 2011 el Estado colombiano, en su artículo $3^{\circ}$, reconoció territorios de los pueblos indígenas como víctimas del conflicto, puesto que para ellos "el territorio es víctima, teniendo en cuenta su cosmovisión y el vínculo especial y colectivo que los une con la madre tierra" (Unidad para la Atención y Reparación Integral a las Víctimas, 2012, p. 14).

Más adelante, en el artículo $45^{\circ}$, este mismo documento da mayores luces frente a la articulación entre cultura y territorio, y el impacto producido por la violencia en él, al expresar que

El territorio, comprendido como integridad viviente y sustento de la identidad y armonía, de acuerdo con la cosmovisión propia de los pueblos indígenas y en virtud del lazo especial y colectivo que sostienen con el mismo, sufre un daño cuando es violado o profanado por el conflicto armado interno y sus factores vinculados y subyacentes. Son daños al territorio aquellos que vulneren el equilibrio, la armonía, la salud y la soberanía alimentaria de los pueblos indígenas y que puedan entenderse conexos con las causas a las que se refiere el artículo $3^{\circ}$ del presente decreto. (Unidad para la Atención y Reparación Integral a las Víctimas, 2012, p. 25)

Con base en lo anterior podríamos retomar los cuestionamientos planteados al inicio de este documento y preguntarnos ¿Podría considerarse también a la naturaleza como titular de esos derechos de forma autónoma? En el marco del actual posacuerdo y en una posterior y real situación de posconflicto ¿¿Debería reconocerse a la naturaleza como sujeto de derechos y, en tanto víctima, reparar los daños causados a ecosistemas durante el conflicto armado? ¿Quién y cómo la resarce? ¿Quién y cómo garantiza la verdad, la restauración y la no repetición?

Reconocer a la naturaleza como sujeto de derechos es entender y admitir social y jurídicamente que más allá de intereses utilitaristas, ella tiene una integridad que debe ser mantenida y que, constantemente, como resultado de conflictos territoriales (de todo tipo, incluidos lógicamente los armados), resulta alterada de forma irreversible. No se trata exclusivamente del reconocimiento del derecho a la vida e integridad que, por supuesto, debe ser conservada o restaurada, sino también, que cualquier actuación sobre ella deba darse con base en el respeto e interacción con sus lógicas, límites, restricciones y tiempos de reproducción y restauración, en diálogo de saberes con ella, si cabe la expresión, y que, en la práctica, el mejor camino para ello es de la mano de quienes mejor la conocen, de quienes han hecho 
parte de su historia y la han incorporado en su cosmogonía, en su corpus social: las comunidades ancestrales, raizales; aquellas en las que naturaleza-historia-culturamitos-realidades-presente y futuro, se funden en el territorio como uno solo. Ello nos conducirá con certeza a construir caminos para reparar a la naturaleza y, a través de una justicia ambiental y espacial, establecer acuerdos que legitimen y viabilicen ese destino. Es importante aclarar que no se trata de poner en marcha, social, política e institucionalmente, movimientos neoludistas, anarco-primitivistas, o ecologistas radicales, sino de incorporar en la concepción, valoración, utilización y transformación de la naturaleza, lógicas más allá de las establecidas por el consumismo, y que respete y valore los ciclos vitales y funcionales de esta, y de aquellos en profunda interacción con ella; es por esto que el concepto y constructo de territorio resulta no solo útil sino muy potente para acercarse a posibilidades de restauración sociohistórica.

Entonces, en la práctica ¿Se puede hablar de la necesidad de construir una MHA? ¿Qué sería? ¿Cómo erigirla? ¿A quiénes se les rendiría cuentas de ella?

Si el mundo ya está empezando a reconocer a la naturaleza como sujeto de derechos, entonces el camino siguiente es hablar, en primera medida, de verdad para que hechos y victimarios, sean conocidos por la sociedad, en especial por los directamente afectados en los territorios impactados y a partir de ellos reconocer y diferenciar los distintos niveles de afectación producidos y los responsables de ellos. Por ejemplo ¿ Conoce el país que el Bloque paramilitar Tolima, usó sistemáticamente las cuencas hidrográficas, especialmente el río Magdalena, en prácticas de desaparición forzada? La Sala de Justicia y Paz del Tribunal Superior de Bogotá (2017) así lo determinó y responsabilizó directamente a Atanael Matajudíos de estos crímenes; en este y en otros casos ejercidos por las Autodefensas Campesinas de Puerto Boyacá y de las Autodefensas Campesinas del Magdalena Medio, bajo el mando de Ramón Isaza (Tribunal Superior de Bogotá, 2014), las sentencias referidas documentan el daño a cuencas hidrográficas y la modificación de sus cauces, por cuanto establecen que el arrojar cuerpos sin vida a los cauces producen un daño sociocultural y colectivo,

ya que muchas de las comunidades ribereñas han dejado de construir su vida en torno al río, han dejado de celebrar festividades y desfiles de balsas en los afluentes del Magdalena y han abandonado sus propiedades en la ribera, por lo que los sistemas de producción campesina en torno a la pesca se han desdibujado. (Eslava, 2019)

Vemos entonces; de una parte, que violencia territorial y daño ambiental van de la mano y que, estas dos, tal como se mostró con el caso del Putumayo, son la semilla para desastres (ambientales, por eventos naturales o socio-naturales), solo 
es cuestión de tiempo; y, de otra parte, que la "Verdad" es el punto de partida para la individualización y responsabilización de victimarios ante la justicia.

Precisamente este es el segundo requisito que demanda la construcción de la MHA, tal como lo determina el $\mathrm{CNMH}$ (2013); "Justicia", que como principio, pretende que la sociedad garantice que cada persona tenga aquello que le corresponde o amerita y que, como acuerdo social, establece un cuerpo de pautas y criterios que definen un marco adecuado para las relaciones sociales, permitiendo, autorizando y/o prohibiendo acciones específicas, en la búsqueda de un bien común, que se entiende, superior al individual. Justicia que en sí misma involucra otros valores que permiten que esta se alcance: equidad, respeto, libertad e igualdad. En estos casos, el conocer la verdad sobre la violencia territorial permite que la institucionalidad y, en su proyección, la sociedad, además de establecer los niveles de responsabilidad jurídica y social que les cabe a los victimarios, imponga en ellos, en condiciones de igualdad y respeto, ciertas sanciones, correctivos o acciones que posibiliten a sus víctimas acceder a entornos de mayor respeto, libertad y equidad, así como a posibilidades ciertas de resarcimiento. Si hacemos esto extensivo a la naturaleza como víctima, entonces se trataría de que la sociedad en general construya valoraciones y prácticas que propendan por mayor respeto y equilibrio en su uso y transformación, en condiciones de equidad en su acceso, para las diversas comunidades.

Por su parte, la "Reparación”, tercera condición de la Memoria histórica, busca restituir, indemnizar, rehabilitar y satisfacer a las víctimas, así como compromiso, condiciones y garantías de no repetición de las conductas criminales. Obligaciones que recaen de forma directa en los victimarios, pero que el Estado, en su condición de ente jurídico y político rector, debe velar y garantizar que se cumplan. Resarcimiento de daños y restablecimiento de derechos, implica no solo acciones legales y pecuniarias, sino morales y sociales, mucho más si la víctima en cuestión es el territorio (naturaleza/sociedad). No repetición de las conductas que agravian al territorio exige, consecuentemente, modificar estructuralmente la relación que se establece con la naturaleza, soporte material del territorio, así como reconocer y respetar otras formas de ver e interpretar el mundo (cosmogonías) y los procesos de construcción histórica, simbólica y cultural que ello conlleva, para actuar en concordancia.

La MHA, entonces, es aquella que permite a la sociedad en su conjunto tener, de forma consciente y colectiva, una serie de hechos, circunstancias o condiciones que definen o configuran un pasado territorial que tiene vigencia y sentido en el presente como expresión de identidad y coherencia social, espacial y cultural. En esta dirección, como memoria vívida trasciende en espacio y en tiempo territarias 45 287

TERRITORIO, VIOLENCIA Y DESASTRES EN COLOMBIA: UN ACERCAMIENTO A LA MEMORIA HISTÓRICA AMBIENTAL 
para plasmar significados y símbolos de reconocimiento colectivo. El territorio entonces, como expresión de una MHA, es pasado, presente y posibilidad de futuro, pero también, es una expresión viva, con identidad propia, más allá de las particularidades del sujeto o la misma naturaleza, entendida cada una de ellas, per se. Si bien es difícil responder de forma concluyente a una de las preguntas formuladas al inicio de este numeral, podría decirse que, no siendo claros aún los argumentos para considerar a la naturaleza como titular de derechos de forma autónoma, sí es más fácil y plausible reconocérselos, por los argumentos ya expuestos, al territorio.

En lo que a la violencia y el conflicto hacen referencia, la MHA atestigua para las generaciones presentes y futuras, situaciones y acciones que degradaron territorio y/o naturaleza, reconociendo allí afectaciones y responsables; las respuestas sociales y culturales frente a ellas, incluidas las acciones que se impusieron como condición de justicia; el resarcimiento generado (reparación de daños y restitución de derechos, y condiciones, en este caso); y símbolos y significados construidos socialmente de ello y que perduran en el tiempo, como expresión misma de esa memoria, y que garantizan, a través del colectivo, la no repetición. Es decir, la MHA va más allá de lo que en la práctica hasta ahora se ha hecho, nombrar, en algunas ocasiones, guardianes o representantes legales que velen por la integridad de los ecosistemas y la vida que allí acogen, en otras, establecer sanciones para quienes generan daños ambientales o sanciones monetarias compensatorias, para inhibir acciones degradantes.

Finalmente, en su vínculo con los desastres, la MHA posibilita tener presente la compleja interacción entre TerritorioViolencia-Desastres, no como condición sine qua non del devenir histórico sino como manifestación, en situaciones de conflictos extremos no resueltos pacíficamente, de profundas inequidades y daños socioespaciales y ambientales que configuran lenta pero certeramente, escenarios vulnerables para la población, que en cuestión de tiempo, se concretan en desastres. La figura de Santiago Nasar, referida mágicamente por Gabriel García Márquez (1981), levantándose a enfrentar su negro destino, establecido de antemano y conocido por muchos, menos por él, podrían bien ilustrar los desastres como crónicas anunciadas. Esperemos entonces que la MHA posibilite, en tanto memoria vívida del territorio, ser instrumento de reducción, primero de conflictos, daños y desastres, dada su condición compensadora y restauradora, y un tiempo después, modificadora, gracias a su peso y significancia social, de las causas generadoras de ellos.

\section{Referencias}

Armada de Colombia. (2018, septiembre 18). Incautamos víveres de contrabando en Putumayo. https://www.

JAVIER ENRIQUe ThOMAS BOHÓRQUEZ 
armada.mil.co/es/content/incautamos-viveres-contrabando-en-putumayo

Aroca Rodríguez, S. P. (2017, 30 de noviembre). Lo sucedido en Mocoa fue un fenómeno natural imprevisible: gobernadora de Putumayo. Blu radio. https://www.bluradio.com/nacion/ lo-sucedido-en-mocoa-fue-un-fenomeno-natural-imprevisible-gobernadora-de-putumayo

Ávila, C. (2017, 21 de diciembre). Putumayo, a merced de una nueva ola de violencia. El Espectador. https:// colombia2020.elespectador.com/territorio/putumayo-merced-de-unanueva-ola-de-violencia, 17-04-2019.

Bermúdez, A., (2018, 27 de septiembre). El contrabando está arruinando este caso exitoso de sustitución de coca. Pacifista! https://pacifista.tv/notas/ el-contrabando-esta-arruinando-estecaso-exitoso-de-sustitucion-de-coca/ Blaikie, P., Canon, T., Davis, I., \& Wisner, B. (1996). Vulnerabilidad. El entorno social, politico y económico de los desastres. La RED.

Bohle, H. (2001, l de enero). Vulnerability and criticality: Perspectives from Social Geography. International Human Dimensions Programme on Global Environmental Change, IHDP 2. https://www.researchgate. net/publication/281020579_Vulnerability_and_Criticality_Perspectives_from_Social_Geography
Calabi, D., \& Indovina, F. (1973). Sull'uso capitalistico del territorio. Archwio di Studi Urbanz e Regionali, (2), Franco Angeli Editore.

Castells, M. (1976). La cuestión urbana ( $2^{\text {a }}$ ed.). Siglo XXI.

Centro Nacional de Memoria Histórica (CNMH). (2013). Basta ya Colombia: Memorias de guerra y dignidad. Imprenta Nacional de Colombia.

Conexión Putumayo, (2019). Propinan golpe contra la minería ilegal en el río Cocayá de Puerto Caicedo. Conexión Putumayo. http://www. conexionputumayo.com/propinangolpe-contra-la-mineria-ilegal-en-elrio-cocaya-de-puerto-caicedo/

Convención de Ginebra relativo a la protección de las víctimas de los conflictos armados internacionales. Artículo $35^{\circ}$ [Protocolo adicional I] 8 de junio de 1977. https://www.icrc.org/es/ document/protocolo-i-adicionalconvenios-ginebra-1949-proteccionvictimas-conflictos-armados-internacionales-1977

Corte Suprema de Justicia. Sala de Casación Civil. Poceso STC4360-2018, M. P. Luis Armando Tolosa Villabona; 5 de abril de 2018. https://cortesuprema.gov.co/corte/wp-content/ uploads/2018/04/STC4360-20182018-00319-011.pdf

Cutter, S. L, Boruff, B. J., \& Shirley, W. L. (2003, junio). Social Vulnerability to Environmental Hazards. Social 
Science Quarterly, 84(2), 242-261. https://doi.org/10.1111/15406237.8402002

Decreto Ley 4633 de 2011 . Por medio del cual se dictan medidas de asistencia, atención, reparación integral y de restitución de derechos territoriales a las víctimas pertenecientes a los pueblos y comunidades indígenas [Decreto Ley de víctimas]. Diario oficial N. ${ }^{\circ} 48.278$ de 9 de diciembre de 2011.

Departamento Administrativo Nacional de Estadísticas (DANE). (2005). Información Básica Censo General. https:// www.dane.gov.co/index.php/estadisticas-por-tema/demografia-y-poblacion/censo-general-2005-1

Departamento Nacional de Planeación (DNP). (2015). Encuesta Nacional de Logística. [Resultados Nacionales]. https://plc.mintransporte.gov.co/ Publicaciones/Encuesta-NacionalLog\%C3\%ADstica

Departamento Administrativo Nacional de Estadísticas (DANE). (2017). Medición de pobreza monetaria y desigualdad. http://microdatos.dane.gov.co/index.php/catalog/MICRODATOS/ about_collection $/ 27 / 4$

Eslava, G. (2019). Naturaleza: ¡ंvíctima del conflicto? De Justicia. https://www. dejusticia.org/naturaleza-victima-delconflicto/

García, G. (1981). Crónica de una muerte anunciada. Norma.

territarias 45

Gobernación del Putumayo. (2017). Análisis cartográfico del Posconflicto en el
Departamento del Putumayo. https:// colombia.iom.int/sites/colombia/files/Cartilla\%20Putumayo\%20web.pdf Gobierno de Colombia. (2004). Censo de cultivos ilicitos en diciembre de 2003 [Informe]. Ministrio del interior y Justicia; Dirección nacional de estupefacientess (DNE) Policía Antinarcóticos de Colombia (DIRAN). http://www. odc.gov.co/Portals/1/publicaciones/ pdf/oferta/censos/OF02012003censo-cultivos-coca-2003-.pdf

Grimson, A. (2003). Los procesos de fronterización: flujos, redes e historicidad. En García C. (Comp.), Fronteras, territorio y metáforas (pp. 15-33). Instituto de estudios regionales (INER), Universidad de Antioquia.

Harvey, D. (2008). La condición de la posmodernidad. Investigación sobre los origenes del cambio cultural. Amorrortu.

Instituto Geográfico Agustín Codazzi (IGAC). (2012). Atlas de la distribución de la propiedad rural en Colombia. Imprenta Nacional de Colombia.

Latour, B. (2001). La esperanza de Pandora: ensayos sobre la realidad de los estudios de la ciencia. Gedisa.

Lavell, A., (1993). Ciencias Sociales y desastres naturales en América Latina: Un encuentro inconcluso. EURE, 19(58), 73-84. https://repositorio. uc.cl/handle/11534/4001

Lavell, A., (2008). Una visión de futuro: La gestión del riesgo [archivo pdf]. https://www.academia. edu/9808475/Una_Visi\%C3\%B3n_

JAVIER ENRIQUe ThOMAS BOHÓRQUEZ 
de_Futuro_La_Gesti\%C3\%B3n_del_ Riesgo

Lefebvre, H. (1995). Introduction to Modernity. Verso.

Lussault, M. (2007). El hombre espacial. La construcción social del espacio humano. Amorrortu.

Martínez, A., \& Delgado, M. (2017). Estudio sobre el impacto de la actividad petrolera en las regiones productoras de Colombia.[Informe de Fedesarrollo a Ecopetrol S.A.-Caracterización departamental Putumayo]. https:// www.repository.fedesarrollo.org.co/ bitstream/handle/11445/3509/ Repor_Septiembre_2017_ Martinez_y_Delgado_Putumayo. pdf? sequence $=4 \&$ is Allowed $=\mathrm{y}$

Oficina de la Naciones Unidas contra la droga y el delito (UNODC). (2017). Colombia. Monitoreo de territorios afectados por cultivos ilicitos 2016. https://www.unodc.org/documents/ colombia/2017/julio/CENSO_2017_ WEB_baja.pdf

Oficina de la Naciones Unidas contra la droga y el delito (UNODC). (2013). Atlas de la caracterización regional de la problemática asociada a las drogas ilicitas en el departamento del Putumayo. http://www.odc.gov.co/Portals/1/politica-regional/Docs/2016/ REATLAS0637_putumayo.pdf

Programa de las Naciones Unidas para el Desarrollo (PNUD). (2009, junio). El rompecabezas de la restitución de tierras. Hechos del Callejón, (47), 1-20. https://info.undp.org/docs/pdc/ Documents/COL/00058220_hechos\%2047.pdf

Programa de las Naciones Unidas para el Desarrollo (PNUD). (2011). Colombia rural. Razones para la esperan$z a$ [Informe Nacional de Desarrollo Humano, 2011]. http://hdr.undp. org/sites/default/files/nhdr_colombia_2011_es_low.pdf

Romero, G., \& Maskrey, E. (1993). Cómo entender los desastres naturales. En A. Maskrey (Comp.), Los desastres no son naturales (pp. 6-10). La RED; Tercer mundo.

Sánchez, L. (2012). La ciudad-refugio: migración forzada y reconfiguración territorial urbana en Colombia: el caso Mocoa. Universidad del Norte; Consejo Profesional de Arquitectura y sus Profesiones Auxiliares.

Santos, B. (1998). De la mano de Alicia: lo social y lo politico en la postmodernidad. Siglo del Hombre; Facultad de Derecho, Universidad de los Andes.

Santos, M. (2000). La naturaleza del espacio. Técnica y tiempo. Razón y emoción. Ariel Geografía.

Schmidt, A. (1977). El concepto de naturaleza en Marx. Siglo XXI.

Thomas, J. E. (2011). Desarrollo y gestión social del riesgo: ¿Una contradicción histórica? Revista de Geografía Norte Grande, (48), 133-157. http:// dx.doi.org/10.4067/S 0718 34022011000100008 territarias 45 291 
Tribunal Superior de Bogotá. Sala de Justicia y Paz. Sentencia 1520. M. P. Eduardo Castellanos Roso; 29 de mayo de 2014. https://www.fiscalia.gov.co/colombia/wp-content/ uploads/2014/12/2014-05-2982855-RAMON-ISAZA.pdf

Tribunal Superior de Bogotá. Sala de Justicia y Paz. Radicado interno 1177. M. P. Eduardo Castellanos Roso; 23 de mayo de 2017. https://www.fiscalia.gov.co/colombia/wp-content/ uploads/2017/06/2017-05-23-Inda-
lecio-Jos\%C3\%A9-S\%C3\%AlnchezJaramillo-Primera.pdf

Unidad para la Atención y Reparación Integral a las Víctimas. (2012). Decreto Ley de Victimas No. 4633 de 2011 [Colección cuadernos legislación y pueblos indígenas de Colombia No. 3]. Imprenta Nacional de Colombia. Wilches, G. (1993). La vulnerabilidad global. En A. Maskrey (Comp.), Los desastres no son naturales (pp. 11-44). La RED; Tercer mundo. 